\title{
Structure and substrate ion binding in the sodium/proton antiporter PaNhaP
}

\author{
David Wöhlert, Werner Kühlbrandt*, Özkan Yildiz* \\ Department of Structural Biology, Max Planck Institute of Biophysics, Frankfurt \\ am Main, Germany
}

\begin{abstract}
Sodium/proton antiporters maintain intracellular $\mathrm{pH}$ and sodium levels. Detailed structures of antiporters with bound substrate ions are essential for understanding how they work. We have resolved the substrate ion in the dimeric, electroneutral sodium/proton antiporter PaNhaP from Pyrococcus abyssi at $3.2 \AA$, and have determined its structure in two different conformations at $\mathrm{pH} 8$ and $\mathrm{pH}$ 4. The ion is coordinated by three acidic sidechains, a water molecule, a serine and a main-chain carbonyl in the unwound stretch of trans-membrane helix 5 at the deepest point of a negatively charged cytoplasmic funnel. A second narrow polar channel may facilitate proton uptake from the cytoplasm. Transport activity of $\mathrm{PaNhaP}$ is cooperative at $\mathrm{pH} 6$ but not at $\mathrm{pH}$ 5. Cooperativity is due to $\mathrm{pH}$-dependent allosteric coupling of protomers through two histidines at the dimer interface. Combined with comprehensive transport studies, the structures of PaNhaP offer unique new insights into the transport mechanism of sodium/proton antiporters.
\end{abstract}

DOI: 10.7554/eLife.03579.001

\begin{abstract}
*For correspondence: werner. kuehlbrandt@biophys.mpg.de (WK); Oezkan.Yildiz@biophys. mpg.de (ÖY)
\end{abstract}

Competing interests: See page 18

Funding: See page 18

Received: 06 June 2014

Accepted: 25 November 2014

Published: 26 November 2014

Reviewing editor: Richard Aldrich, The University of Texas at Austin, United States

(c) Copyright Wöhlert et al. This article is distributed under the terms of the Creative Commons Attribution License, which permits unrestricted use and redistribution provided that the original author and source are credited.

\section{Introduction}

The $\mathrm{Na}^{+} / \mathrm{H}^{+}$antiporter NhaP from Pyrococcus abyssi (PaNhaP) exchanges protons against sodium ions across the cell membrane. PaNhaP is a functional homologue of the human $\mathrm{Na}^{+} / \mathrm{H}^{+}$exchanger $\mathrm{NHE1}$, which controls intracellular $\mathrm{pH}$ and $\mathrm{Na}^{+}$concentration. NHE1 is an important drug target (Karmazyn et al., 1999), but its structure and detailed mode of action are unknown. Transport mechanisms of eukaryotic membrane proteins are conserved in the more robust prokaryotic transporters from thermophilic bacteria and archaea (Yamashita et al., 2005; Boudker et al., 2007; Lee et al., 2013). Highresolution structures of such homologues are of great value for understanding the mechanisms of cation/proton antiport, provided that (i) the transported substrate ions are resolved, (ii) structures of the same transporter are available in different conformations, and (iii) kinetic data of substrate binding and transport are available. In this paper we report the structure of the electroneutral $\mathrm{Na}^{+} / \mathrm{H}^{+}$antiporter PaNhaP from the hyperthermophilic archaeon P. abyssi in two different conformations at $\mathrm{pH} 4$ and $\mathrm{pH} 8$, with the substrate ion resolved at $\mathrm{pH}$ 8. We show that, like NHE1, transport by PaNhaP is cooperative in a $\mathrm{pH}$-dependent manner, indicating a $\mathrm{pH}$-dependent allosteric interaction of protomers in the dimer.

The first structure of a cation-proton antiporter (CPA) revealed that Escherichia coli $\mathrm{Na}^{+} / \mathrm{H}^{+} \mathrm{NhaA}$ (EcNhaA) is a dimer in the membrane (Williams et al., 1999). The $6 \AA$ map of EcNhaA resolved 12 transmembrane helices (TMH) in the protomer, arranged in a 6-helix bundle, plus a row of six TMHs at the dimer interface (Williams, 2000). A membrane dimer was also found for the NhaP1 antiporter from Methanocaldococcus jannaschii (MjNhaP1) (Vinothkumar et al., 2005; Goswami et al., 2011; Paulino and Kühlbrandt, 2014). MjNhaP1, PaNhaP and the medically important NHE1 belong to the CPA1 subfamily (Brett et al., 2005) of antiporters, which exchange $\mathrm{Na}^{+}$and protons with 1:1 stoichiometry and are thus electroneutral. By contrast, EcNhaA and TtNapA from Thermus thermophilus, as well as the eukaryotic NHA1-2 and AtChx1 (Brett et al., 2005), belong to the CPA2 subfamily of electrogenic antiporters, which exchange one $\mathrm{Na}^{+}$against two protons. Neither the x-ray structure of EcNhaA (Hunte et al., 2005) nor that of TtNapA (Lee et al., 2013) resolved the substrate ion. 
eLife digest Although the membrane that surrounds a cell is effective at separating the inside of a cell from the outside environment, certain molecules must enter or leave the cell for it to work correctly. One way this transport can occur is via proteins embedded in the cell membrane, called transporters.

Transporters that are found in all organisms include the sodium/proton antiporters, which exchange protons from inside the cell with sodium ions from outside. However, exactly how the antiporter works was unknown.

Previous work suggested that the structure and activity of the sodium/proton antiporter changes as the acidity of its environment changes, but the precise details of how this occurs were unclear. Wöhlert et al. have now crystallised a sodium/proton antiporter from a single-celled organism called Pyrococcus abyssi, a species of archaea that has been found living in hydrothermal vents deep in the Pacific Ocean. The structures the protein takes on in different functional states were then deduced from these crystals using a technique called X-ray crystallography. Using heavy thallium ions instead of sodium ions, which are less visible to X-rays, Wöhlert et al. found the site in the antiporter where the transported ion binds as it moves through the membrane.

The antiporter has a funnel-shaped cavity that faces inwards (into the cell) in both acidic and alkaline conditions, although a second narrow channel that is open in alkaline conditions is blocked in acidic conditions by small protein rearrangements. Wöhlert et al. suggest that the differences between both structures explain how the antiporter tunes its ability to bind to the ions it transports.

Wöhlert et al. further measured the activity of the antiporter and observed that the transport of ions was most rapid under slightly acidic conditions. In more acidic conditions, the sodium ion cannot bind to the antiporter, and in an alkaline environment, the sodium ions bind too strongly to the antiporter; in both cases, the ions cannot be transported.

Comparing the findings presented here with separate work that uncovers the structure of the sodium/proton antiporter in a different species of archaea revealed very similar structures. Related transporters are also found in mammals, and defects in these transporters can lead to problems with the heart and kidneys. A better understanding of the sodium/proton antiporter structure could therefore help to develop new treatments for these conditions.

DOI: 10.7554/eLife.03579.002

\section{Results}

\section{Overall architecture of PaNhaP}

Crystals of seleno-methionine derivatized PaNhaP grown at $\mathrm{pH} 8$ diffracted isotropically to $3.15 \AA$ resolution. The structure was solved by SAD (Tables 1 and 2). Twelve out of the 14 SeMet positions in the asymmetric unit containing one PaNhaP dimer were identified (Figure 1-figure supplement 1). Seen from the cytoplasm, the PaNhaP dimer is roughly rectangular, with a long axis of $90 \AA$ and a short axis of $53 \AA$ (Figure 1A, Figure 1-figure supplement 2A). Each protomer has $13 \mathrm{TMHs}(\mathrm{H} 1-\mathrm{H} 13)$ connected by short loops or helices on the membrane surface. H4-6 and H11-13 form the 6-helix bundle, while $\mathrm{H} 1-3$ and H7-10 form the dimer interface. $\mathrm{H} 1-6$ and $\mathrm{H} 8-13$ are two halves of an inverted 6-helix repeat, connected by $\mathrm{H} 7$. Several helices are highly tilted, especially $\mathrm{H} 7$ and $\mathrm{H} 8$, which include angles of more than $45^{\circ}$ with the membrane normal while others, in particular $\mathrm{H} 6$ and $\mathrm{H} 10$, are bent. $\mathrm{H} 5$ and $\mathrm{H} 12$ in the 6-helix bundle are discontinuous. Their cytoplasmic and extracellular halves (referred to as $\mathrm{H} 5_{\mathrm{C}}, \mathrm{H} 5_{\mathrm{E}}$ and $\mathrm{H} 12_{\mathrm{C}}, \mathrm{H} 12_{\mathrm{E}}$ respectively) are each connected by unwound stretches with antiparallel orientation, which cross one another in the centre of the protomer (Figure 1, Figure 1-figure supplement 2). The membrane surfaces are marked by three short amphipathic helices connecting $\mathrm{H} 3$ to $\mathrm{H} 4$ on the cytoplasmic side, $\mathrm{H} 6$ to $\mathrm{H} 7$ and $\mathrm{H} 10$ to $\mathrm{H} 11$ on the extracellular side. $\mathrm{H} 10$ protrudes by $11 \AA$ on the cytoplasmic surface, and the helix hairpin connecting $\mathrm{H} 12$ to $\mathrm{H} 13$ protrudes by about $7 \AA$ A on the extracellular side. The loops connecting helices $\mathrm{H} 1$ to $\mathrm{H} 2$ and $\mathrm{H} 8$ to $\mathrm{H} 9$ are $\sim 10 \AA$ below the cytoplasmic or extracellular surface (Figure 1B, Figure 1-figure supplement 2B).

On the cytoplasmic side of the protomer, a solvent-filled $\sim 16 \AA$-deep funnel, lined by $\mathrm{H} 3, \mathrm{H} 5_{\mathrm{c}}, \mathrm{H} 6$, and $\mathrm{H} 10$, penetrates to the centre of the protomer between the 6-helix bundle and the dimer interface (Figure 1-figure supplement 3, Video 1). A second, narrow polar channel, lined by the unwound 
Table 1. Data collection and refinement statistics

\begin{tabular}{|c|c|c|c|}
\hline & SeMet @ pH 8 & Thallium @ pH 8 & Native @ pH 4 \\
\hline Data collection & & SLS PXII & \\
\hline Wavelength & 0.979 & 0.979 & 0.978 \\
\hline Space group & $\mathrm{P} 2_{1}$ & $\mathrm{P} 2_{1}$ & $\mathrm{P}_{4}$ \\
\hline \multicolumn{4}{|l|}{ Cell dimensions } \\
\hline$a, b, c(\AA)$ & $54.5,107.9,107.9$ & $54.1,107.4,99.8$ & $109.6,109.6,209.6$ \\
\hline$\alpha, \beta, y\left(^{\circ}\right)$ & $90.0,95.2,90.0$ & $90.0,96.4,90.0$ & $90.0,90.0,120.0$ \\
\hline Resolution (Å) & 48.5-3.15 (3.35-3.15) & 49.6-3.20 (3.40-3.20) & $48.6-3.50(3.72-3.50)$ \\
\hline$R_{\text {pim }}$ & $0.033(0.503)$ & $0.038(0.622)$ & $0.021(0.486)$ \\
\hline$|/ \sigma|$ & $11.9(1.5)$ & $13.4(1.8)$ & $19.9(1.9)$ \\
\hline$C C^{\star}$ & $1.000(0.943)$ & $1.000(0.936)$ & $1.000(0.906)$ \\
\hline Completeness (\%) & 99.5 (99.2) & 99.6 (99.4) & 100.0 (100.0) \\
\hline Multiplicity & 10.8 (10.4) & $17.1(17.4)$ & $9.2(9.1)$ \\
\hline \multicolumn{4}{|l|}{ Refinement } \\
\hline Resolution (Å) & 48.5-3.15 (3.35-3.15) & 49.6-3.20 (3.40-3.20) & $48.6-3.5(3.72-3.5)$ \\
\hline Unique reflections & 38,952 & 34,763 & 33,232 \\
\hline Reflections in test set & 2111 & 1884 & 1782 \\
\hline $\mathrm{R}_{\text {work }} / \mathrm{R}_{\text {free }}(\%)$ & 23.8/27.8 (31.8/39.9) & 24.8/29.5 (35.9/43.4) & 24.1/26.4 (31.8/35.6) \\
\hline CC(work)/CC(free) & 0.843/0.898 (0.842/0.760) & 0.861/0.754 (0.813/0.713) & $0.791 / 0.935(0.749 / 0.617)$ \\
\hline Wilson B-Factor $\left(\AA^{2}\right)$ & 133 & 81 & 146 \\
\hline No. atoms in $\mathrm{AU}$ & 6715 & 6651 & 6592 \\
\hline Protein & 6582 & 6560 & 6560 \\
\hline Ligands & 129 & 81 & 31 \\
\hline Water & 4 & 10 & 1 \\
\hline \multicolumn{4}{|l|}{ r.m.s. deviations: } \\
\hline Bond lengths $(\AA)$ & 0.003 & 0.003 & 0.009 \\
\hline Bond angles $\left({ }^{\circ}\right)$ & 0.758 & 0.714 & 1.002 \\
\hline
\end{tabular}

DOI: 10.7554/eLife.03579.003

stretches of $\mathrm{H} 5_{c}, \mathrm{H} 12_{c}$ and the cytoplasmic halves of $\mathrm{H} 6$ and $\mathrm{H} 13$, extends from the cytoplasmic surface to the region near the deepest point of the funnel (Figure 1-figure supplement 3, Video 1). On the extracellular side, a deep cavity on the twofold axis of the dimer, lined by interface helices $\mathrm{H1}, \mathrm{H} 3$, $\mathrm{H} 8$ and $\mathrm{H10}$, extends $\sim 27 \AA$ into the hydrophobic protein interior. Electron density in this cavity indicated bound lipid (Figure 2), which was identified by thin-layer chromatography as phosphatidyl ethanolamine (PE), carried over from the E. coli expression host. The lipid stretches from the 6-helix bundle of one protomer to the interface helices $\mathrm{H} 3$ and $\mathrm{H} 10$ of the other, providing a hydrophobic link between them. The cavity is large enough to accommodate two lipids, only one of which was resolved in the dimer (Figure 2). The surface potential of the dimer indicates clusters of charged residues on both sides of the membrane (Figure 2-figure supplement 1). The cytoplasmic ends of $\mathrm{H} 10$ and H7 are positively charged, carrying a total of seven lysine and arginine residues. The deep funnel on the cytoplasmic surface is lined by negative charges, which would attract positively charged substrate ions.

\section{The ion-binding site}

Crystals of PaNhaP grown at pH 8 soaked with thallium acetate diffracted to $3.2 \AA$ (Table 1). Two thallium ions were identified in the dimer by anomalous scattering, one each near the deepest point of the cytoplasmic funnel in the two protomers (Figure 1-figure supplement 3, Video 1, Figure 3A). The $\mathrm{Tl}^{+}$ions were located $\sim 14 \AA$ below the cytoplasmic surface and $\sim 22 \AA$ from the extracellular surface. The ion-binding site is accessible from the cytoplasm but not from the extracellular side, so that the structure shows the inward-open conformation of PaNhaP (Figure 1-figure supplement 3, Video 1). 
Table 2. Data collection and phasing statistics

\begin{tabular}{|c|c|c|c|}
\hline & Dataset 1 & Dataset 2 & Merge \\
\hline Data collection & SLS PXII & & \\
\hline Wavelength & 0.979 & 0.979 & 0.979 \\
\hline Space group & $\mathrm{P} 2_{1}$ & $\mathrm{P} 2_{1}$ & $\mathrm{P} 2_{1}$ \\
\hline \multicolumn{4}{|l|}{ Cell dimensions } \\
\hline$a, b, c(\AA)$ & $54.7,109.0,110.8$ & $54.6,108.3,110.5$ & $54.7,108.9,110.7$ \\
\hline$\alpha, \beta, \gamma\left({ }^{\circ}\right)$ & $90.0,94.6,90.0$ & $90.0,95.0,90.0$ & $90.0,94.7,90.0$ \\
\hline Resolution (Å) & $49.3-3.8(3.97-3.8)$ & 49.0-3.8 (3.97-3.8) & $49.2-3.8(3.97-3.8)$ \\
\hline$R_{\text {pim }}$ & $0.029(0.470)$ & $0.034(0.228)$ & $0.036(0.315)$ \\
\hline$|/ \sigma|$ & $13.8(2.1)$ & $12.4(3.9)$ & $14.5(2.9)$ \\
\hline $\mathrm{CC}^{*}$ & $1.000(0.929)$ & $0.996(0.985)$ & $1.000(0.981)$ \\
\hline Completeness (\%) & $99.7(99.7)$ & $99.7(99.6)$ & $100(100)$ \\
\hline Multiplicity & $24.5(16.5)$ & $9.1(9.5)$ & $33.0(25.8)$ \\
\hline \multicolumn{4}{|l|}{ Phasing } \\
\hline CCanom & & & 0.348 \\
\hline Anom slope & & & 1.061 \\
\hline FOM after Phasing (Refmac) & & & 0.230 \\
\hline FOM after DM (Parrot) & & & 0.594 \\
\hline
\end{tabular}

Like $\mathrm{Na}^{+}$and $\mathrm{Li}^{+}$, but unlike $\mathrm{K}^{+}, \mathrm{Tl}^{+}$is a substrate of $\mathrm{PaNhaP}$ (Figure 4). The thallium ions and their surroundings provide a unique view of the ion-binding site and substrate ion coordination in sodiumproton antiporters (Figure 3B,C). Three acidic side chains in three different TMHs contribute to substrate ion-binding. The carboxyl groups of Glu73 in H3 and Asp159 in H6 coordinate the substrate ion directly. Asp130 in the unwound stretch of H5 interacts with the ion via a bound water molecule (Figure 3). The main-chain carbonyl of Thr129, likewise in the unwound stretch of $\mathrm{H} 5$, and the hydroxyl side chain of Ser155 in $\mathrm{H} 6$ provide two additional ligands, bringing the total up to five. The ion coordination geometry is that of a distorted trigonal bipyramid, with Asp159, Ser155 and the water molecule forming a triangle around the central substrate ion, and the Thr129 main chain carbonyl and Glu73 at the tips of the bipyramid (Figure 3B,C).

The second, narrow polar channel next to the cytoplasmic funnel (Figure 1-figure supplement 3, Video 1) leads to an enclosed polar cavity near Asp93, Thr129, Asn158 and the ion pair Glu154/ Arg337, which are highly conserved in the CPA1 antiporters (Goswami et al., 2011). A water molecule in the enclosed cavity links the functionally important groups that surround it. The Glu154/Arg337 ion bridge and Thr129 separate the cavity from the narrow polar channel. The ion-binding site at the end of the cytoplasmic funnel is accessible from both the polar cavity and the narrow polar channel via Thr129, Ser155, and Asn158 (Figure 1-figure supplement 3, Video 1, Figure 3).

\section{Conformational changes at pH 4}

The structure of $\mathrm{PaNhaP}$ crystals grown at $\mathrm{pH} 4$ was determined at $3.5 \AA$ (Table 1) by molecular replacement. As at $\mathrm{pH} 8$, the ion-binding site is accessible from the cytoplasm via the cytoplasmic funnel, but not from the extracellular side. Both structures therefore show an inward-open state. In contrast to the $\mathrm{pH} 8$ structure, the second narrow polar channel is blocked at $\mathrm{pH} 4$ by rearrangements of the surrounding residues Ile151, Phe355, Gly359. The most conspicuous differences to the $\mathrm{pH} 8$ structure are observed near the dimer interface. At pH 8, the His292 sidechains in $\mathrm{H} 10$ of the two protomers form a $15 \AA$ chain of hydrogen bonds with the Glu233 residues near the cytoplasmic ends of H8 (Figure 5, Video 2, Figure 5-figure supplement 1). At pH 4, each of the two histidines moves by 6-8 $\AA$, apparently due to electrostatic repulsion upon protonation at acidic $\mathrm{pH}$ (Figure 2-figure supplement 1). This $\mathrm{pH}$-induced conformational change disrupts the chain of hydrogen bonds linking the two protomers (Figure 5-figure supplement 1). Other major $\mathrm{pH}$-induced changes are found in 


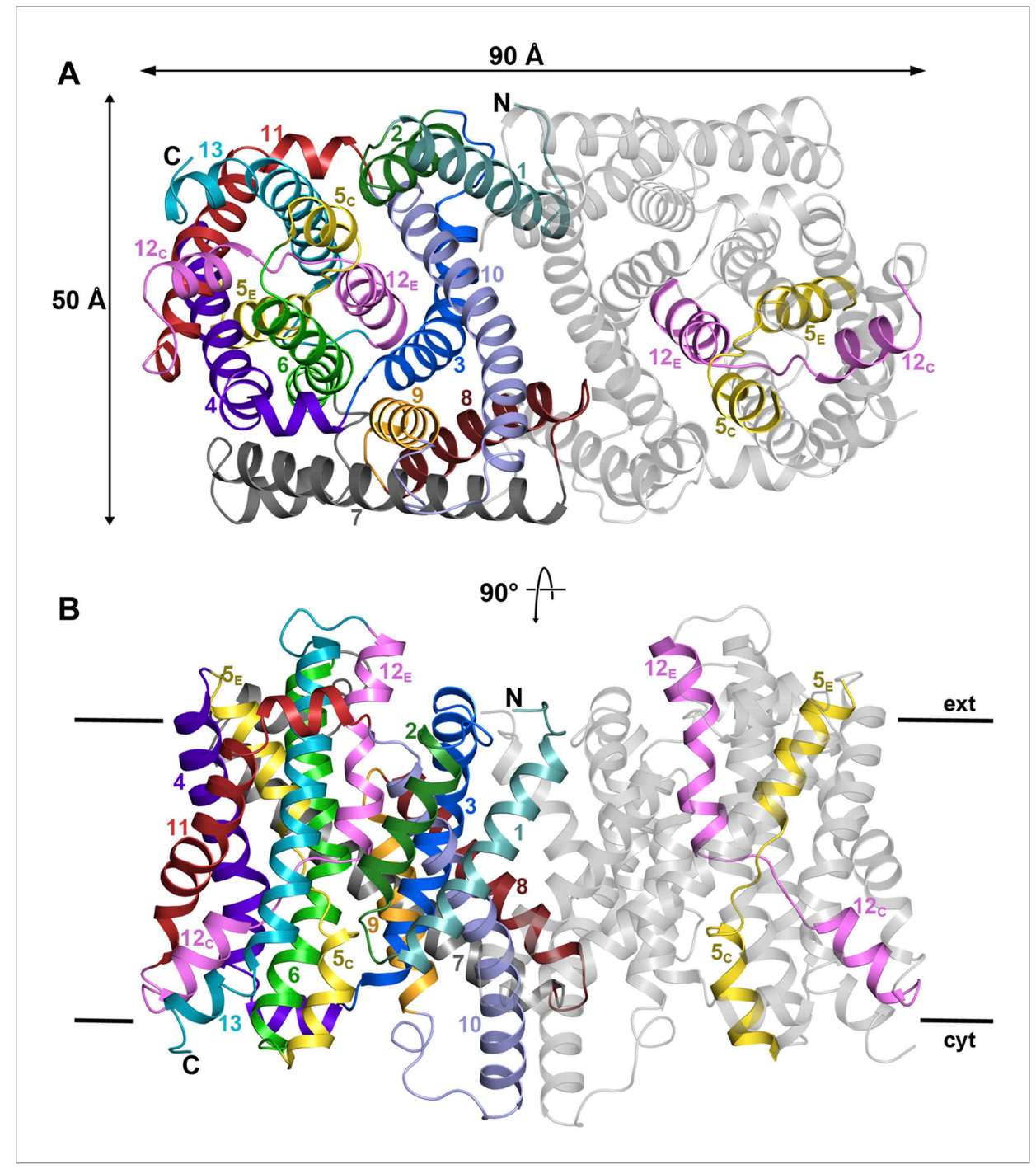

Figure 1. PaNhaP at $\mathrm{pH}$ 8. (A) Cytoplasmic view of the PaNhaP dimer. Helices $\mathrm{H} 1$ to $\mathrm{H} 13$ are color-coded and numbered in one protomer. In the other protomer only the partly unwound helices $\mathrm{H} 5$ and $\mathrm{H} 12$ are coloured. (B) Side view with the C-terminus of helix $\mathrm{H} 13$ on the cytoplasmic side. DOI: 10.7554/eLife.03579.005

The following figure supplements are available for figure 1:

Figure supplement 1. Experimental electron density map of PaNhaP. DOI: 10.7554/eLife.03579.006

Figure supplement 2. X-ray structure of $\mathrm{PaNhaP}$. DOI: 10.7554/eLife.03579.007

Figure supplement 3. Hydrophilic cavities in PaNhaP. DOI: 10.7554/eLife.03579.008

the ion bridges linking the protomers across the dimer interface (Figure 5-figure supplement 1). At $\mathrm{pH}$ 8, Arg25/Glu228 and Arg26/Asp231 connect the cytoplasmic ends of $\mathrm{H} 8$ and H1, while the Glu8/ Arg249 bridge links the extracellular ends of these helices. At pH 4, all six ion pairs break, apparently due to partial protonation of the acidic sidechains, so that each protomer tilts away from the dimer interface (Video 2, Figure 5-figure supplement 1).

Other significant $\mathrm{pH}$-induced differences occur at the $\mathrm{N}$-terminus of the protomer, where residues 3-6 become ordered at $\mathrm{pH} 4$, so that $\mathrm{H} 1$ extends by one turn, and shifts by $3 \AA$ towards the cytoplasmic side (Figure 5-figure supplement 1). In the ion-binding site itself, the sidechain of Asp130 in protomer A moves by $2.7 \AA$ into the space that is occupied by the substrate ion at pH 8 


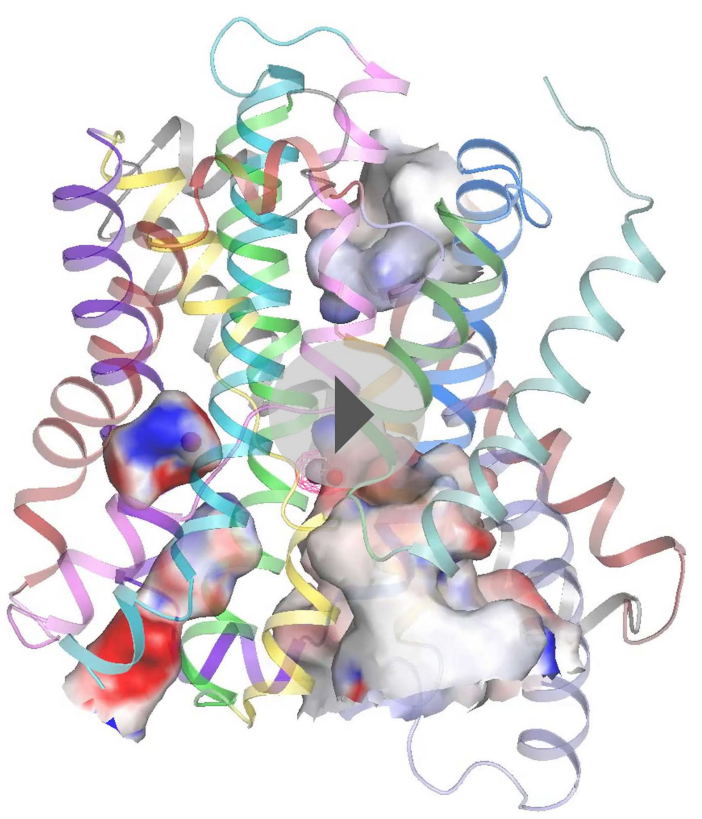

Video 1. Movie of PaNhaP monomer with hydrophilic cavities.

DOI: 10.7554/eLife.03579.009 the dimer interface are relayed to the ion-binding site to modulate the $\mathrm{Na}^{+}$binding affinity in a $\mathrm{pH}-$ dependent manner (Figure 6).

\section{pH-dependent cooperativity}

${ }^{22} \mathrm{Na}$ uptake into reconstituted $\mathrm{PaNhaP}$ proteoliposomes is strongly $\mathrm{pH}$-dependent (Figure 6A). Transport activity was highest at $\mathrm{pH} 5$, dropping to about $75 \%$ at $\mathrm{pH} 6,20 \%$ at $\mathrm{pH}$, and to background level at $\mathrm{pH} 8$. At $\mathrm{pH} 4$, the activity was about $5 \%$ of the peak value at $\mathrm{pH} 5$, resulting in a roughly bell-shaped $\mathrm{pH}$ profile. Sodium uptake measurements performed with reconstituted, insideacidic proteoliposomes (Figure $\mathbf{6 B}, \mathbf{C}$ ) or sodium efflux measurements under symmetrical pH conditions (Figure 6-figure supplement 1A) showed comparable transport behaviour at basic $\mathrm{pH}$. Valinomycin had no effect on the transport rate (Figure 6-figure supplement 1B), demonstrating that $\mathrm{PaNhaP}$ is electroneutral. Measurements of ${ }^{22} \mathrm{Na}^{+}$uptake at $\mathrm{pH} 6$ revealed clear positive cooperativity, with a Hill coefficient of 1.9 (Figure 6C, Figure 6-figure supplement 2B). Since PaNhaP forms stable dimers in detergent solution and each protomer binds only one substrate ion at a time, this indicates that the interaction of protomers across the dimer interface is allosteric, such that at $\mathrm{pH} 6$, an ion binding to one protomer increases the binding affinity of the other, as indicated by the $\mathrm{K}_{0.5}$ value of $25 \mu \mathrm{M}$ (Figure $6 \mathrm{C}$ ), compared to the $\mathrm{K}_{\mathrm{m}}$ of $506 \mu \mathrm{M}$ at pH 5 (Figure 6C). At the pH 5 activity maximum the Hill coefficient was $\sim 1$, indicating non-cooperative transport (Figure 6B, Figure 6-figure supplement 2). Note that the $\mathrm{pH}$-dependent allosteric change of the dimer is different from the inside-open to outside-open transition in the transport cycle of the protomer.

\section{Transport activity}

At room temperature, $\mathrm{v}_{\max }$ of $\mathrm{PaNhaP}$ at the $\mathrm{pH} 5$ activity maximum was $87.9 \mathrm{nmol} \cdot \mathrm{min}^{-1} \cdot \mathrm{mg}^{-1}$, giving a transport rate of $4.4 \pm 0.4 \mathrm{Na}^{+}$ions per minute for each protomer. Between $20^{\circ} \mathrm{C}$ and $45^{\circ} \mathrm{C}, \mathrm{v}_{\max }$ grew exponentially by a factor of 2.1 for every $5^{\circ} \mathrm{C}$ rise in temperature (Figure $7 \mathrm{~A}, \mathrm{~B}$ ) according to the Arrhenius equation. Extrapolation to $100^{\circ} \mathrm{C}$, the physiological temperature for $P$. abyssi, suggests a rate of about 5000 ions per second. Note that temperature affects the transport rate but not substrate binding (Figure $7 C, D$ ).

Residues involved in substrate binding were replaced and the transport activity of mutant proteins was measured in proteoliposomes. Replacement of both ion-coordinating aspartates (Asp130 and Asp159) by serine abolished transport completely (Figure 8A), whereas mutation of Glu73 to alanine 


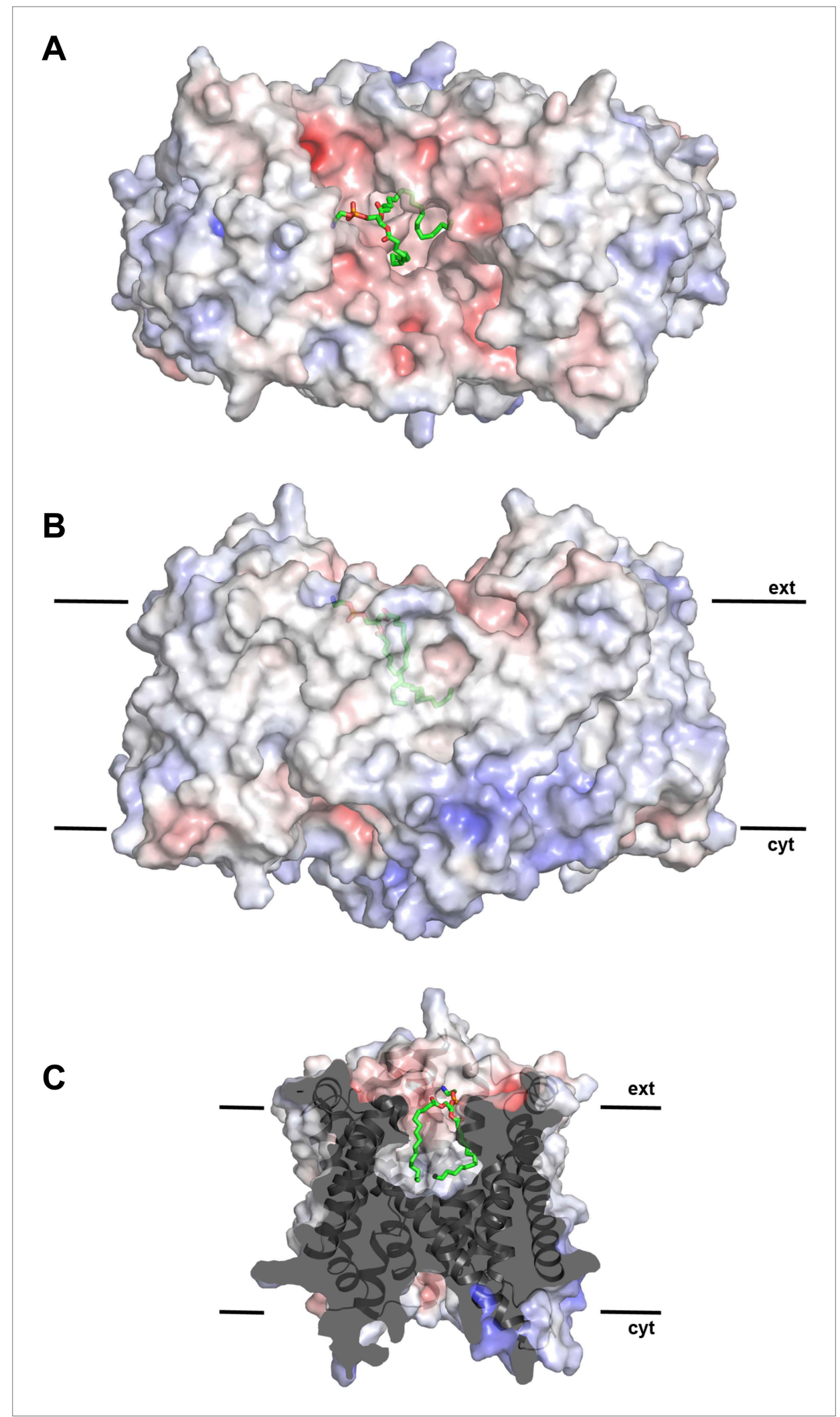

Figure 2. Hydrophobic extracellular cavity with bound lipid. (A) One lipid molecule (PE, green) in the cavity between the two protomers in the dimer contributes to the hydrophobic contacts across the dimer interface. The extracellular surface is slightly negatively charged. (B) The alkyl chain of the lipid extends to the center of the Figure 2. Continued on next page 
Figure 2. Continued

molecule. (C) The lipid-facing surface of the central cavity is mainly hydrophobic. The surface potential was calculated at $\mathrm{pH} 7.0$ by APBS.

DOI: $10.7554 /$ LLife. 03579.010

The following figure supplement is available for figure 2 :

Figure supplement 1. pH-dependent charge distribution.

DOI: 10.7554/eLife.03579.011

increased the activity (Figure 8B), most likely because the substrate ion is released more readily from the binding site. Changing Ser155 to alanine had no significant effect, but mutation of Thr129 to valine that takes this position in eukaryotic CPA1 transporters (Goswami et al., 2011), reduced the activity significantly. This was surprising, because Thr129 coordinates the substrate ion not by its sidechain but by its main-chain carbonyl. However the Thr129 sidechain is a potential interaction partner of the conserved Asn158 that may control access to the ion-binding site through the narrow polar channel. A hydrophobic valine in place of Thr129 would interrupt the local network of hydrogen bonds, which could affect ion binding or proton translocation. A mutant in which His292 was replaced by cysteine migrates as a dimer under oxidizing conditions in SDS-PAGE (Figure 8-figure supplement 1A). The activity of the crosslinked dimer was $35 \%$ of wildtype (Figure 8-figure supplement 1B). Under reducing conditions, when the disulfide bridge between the protomers is broken, activity increases to $150 \%$ of wildtype, highlighting the importance of this position for the regulation of transport.

\section{Discussion}

\section{Ion coordination}

The trigonal bipyramidal coordination geometry of sodium ions observed in PaNhaP is not uncommon in membrane transporters (Penmatsa et al., 2013). The same geometry is found in c-rings of $\mathrm{Na}^{+}-$ translocating F-type ATPase of I. tartaricus and F. nucleatum (Meier et al., 2009; Schulz et al., 2013), which, like the archaeal CPA1 antiporters, bind and release $\mathrm{Na}^{+}$in rapid exchange. Although the ion radius of monovalent $\mathrm{Tl}^{+}(1.5 \AA)$ is similar to that of $\mathrm{K}^{+}(1.44 \AA)$ and larger than that of $\mathrm{Na}^{+}(1.12 \AA)$ (Shannon, 1976; Cotton and Wilkinson, 1988), $\mathrm{Tl}^{+}$is able to replace $\mathrm{Na}^{+}$in $\mathrm{PaNhaP}$. The same has been found for the $\mathrm{Na}^{+}$-dependent aspartate transporter Gl $\mathrm{t}_{\mathrm{Ph}}$ (Boudker et al., 2007), the mammalian glutamate transporter EAAC1 (Tao et al., 2008) and fructose-1,6-biphosphatase (Villeret et al., 1995). In $\mathrm{Glt}_{\mathrm{Ph}}, \mathrm{Na}^{+}$but not $\mathrm{K}^{+}$competes for $\mathrm{Tl}^{+}$binding, and $\mathrm{Tl}^{+}$inhibits $\mathrm{Na}^{+}$-driven aspartate transport (Boudker et al., 2007). Coordination geometry and ligand distances for $\mathrm{Tl}^{+}$in $\mathrm{PaNhaP}$ are similar to those typically found for protein-bound $\mathrm{Na}^{+}$in the PDB (Harding, 2002). The larger ion radius of $\mathrm{Tl}^{+}$may account for the lower transport rate in $\mathrm{PaNhaP}$. However, $\mathrm{Tl}^{+}$is a much better substrate than $\mathrm{K}^{+}$, which is not transported at all (Figure 4). The selectivity for $\mathrm{Na}^{+}$over $\mathrm{K}^{+}$is reminiscent of the striking selectivity of sodium channels, which is thought to be related to ion solvation (Roux et al., 2011). Presumably, the same principle applies to the $\mathrm{Na}^{+} / \mathrm{H}^{+}$antiporters. The water molecule between the sidechain of Asp130 and $\mathrm{Tl}^{+}$indicates that the bound substrate ion retains part of its hydration shell, as complete dehydration is energetically unfavourable.

In $\mathrm{PaNhaP}$, all ion-binding residues are found in the first half of the inverted repeat. Interestingly, the structure and interaction of the ion-coordinating Asp159 and Ser155 in H6 resemble those of the inversely oriented Glu408 and Ser404 in H13 in the second half of the inverted repeat (Figure 3A,D). This may imply that an early form of the CPA1 antiporters, which must have arisen by gene duplication of an unknown precursor, had a second, symmetrical ion-binding site that has been lost in the course of evolution. Arg362 in the unwound stretch of H12, which is essential in MjNhaP1 (Hellmer et al., 2003) and completely conserved in the CPA1 antiporters (Hellmer et al., 2003; Goswami et al., 2011), may be a tethered positive charge that takes the place of the $\mathrm{Na}^{+}$ion in the second half of the inverted repeat, in a way similar to the arginine that replaces the co-transported $\mathrm{Na}^{+}$in the sodiumindependent substrate/product antiporter CaiT (Kalayil et al., 2013).

\section{Regulation of transport activity}

The transport activity of $\mathrm{PaNhaP}$ is highest at $\mathrm{pH} 5$ and declines at higher or lower $\mathrm{pH}$. The resulting bell-shaped $\mathrm{pH}$ profile is explained in terms of the $\mathrm{Na}^{+}$affinity of the acidic residues in the substrate-binding pocket. The protonation state of these is likely to affect the affinity of the binding site 


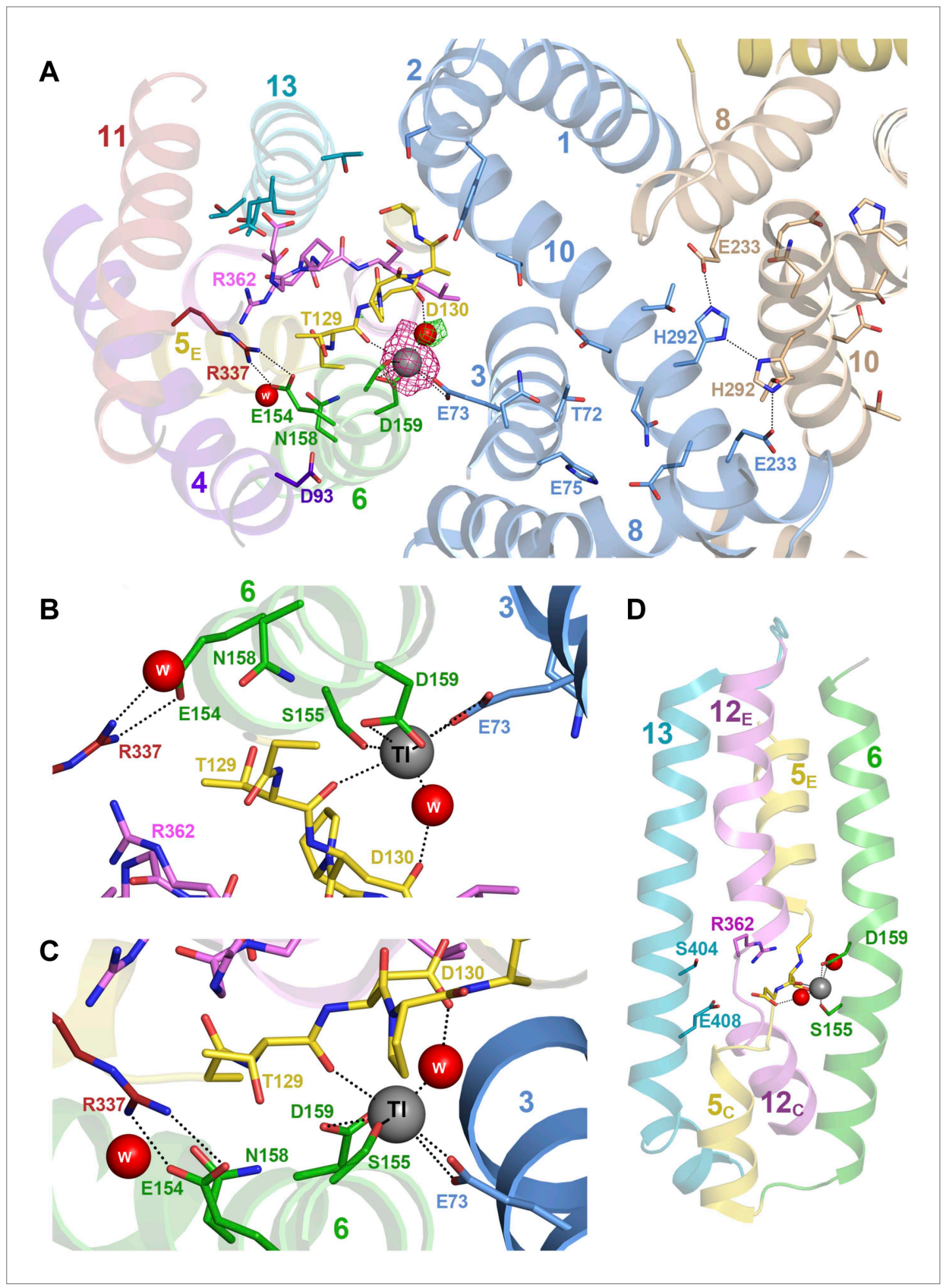

Figure 3. Substrate ion coordination in PaNhaP. (A) Section view of the ion-binding site and interface region of PaNhaP from the cytoplasmic side. Interface helices of the two protomers are shown in blue and beige, respectively. The acidic side chains of Glu73, Asp159, a water molecule held by Asp130, the hydroxyl group of Ser155 and the main-chain carbonyl of Thr129 coordinate the substrate ion. The anomalous density for the $\mathrm{Tl}^{+}$ion (grey sphere) in the substrate-binding site between helix $\mathrm{H} 3, \mathrm{H} 6$ and the unwound stretch of $\mathrm{H} 5$ is shown in magenta at $4 \sigma$. The $3 \sigma$ omit map for the $\mathrm{H}_{2} \mathrm{O}$ molecule next to $\mathrm{Tl}^{+}$is green. The water molecule near Glu154 and Asn158 is not directly involved in ion coordination. (B, C) Detailed views of the substrate-coordinating residues from the extracellular and cytoplasmic side, respectively. (D) Side view of core helices and substrate-binding residues in the 6-helix bundle. DOI: 10.7554/eLife.03579.012

for $\mathrm{Na}^{+}$. At low pH, most if not all of the ion-coordinating carboxyl sidechains (Glu73, Asp130, and Asp159) would be protonated, resulting in reduced affinity for $\mathrm{Na}^{+}$, as has been shown for MjNhaP1 by electrophysiological measurements on solid-supported membranes (Calinescu et al., 2014). At pH 5-7 these carboxyl sidechains would be increasingly deprotonated and able to bind and release $\mathrm{Na}^{+}$ions, as is necessary for transport. At $\mathrm{pH}>7$, the ion-binding site is predominantly deprotonated 


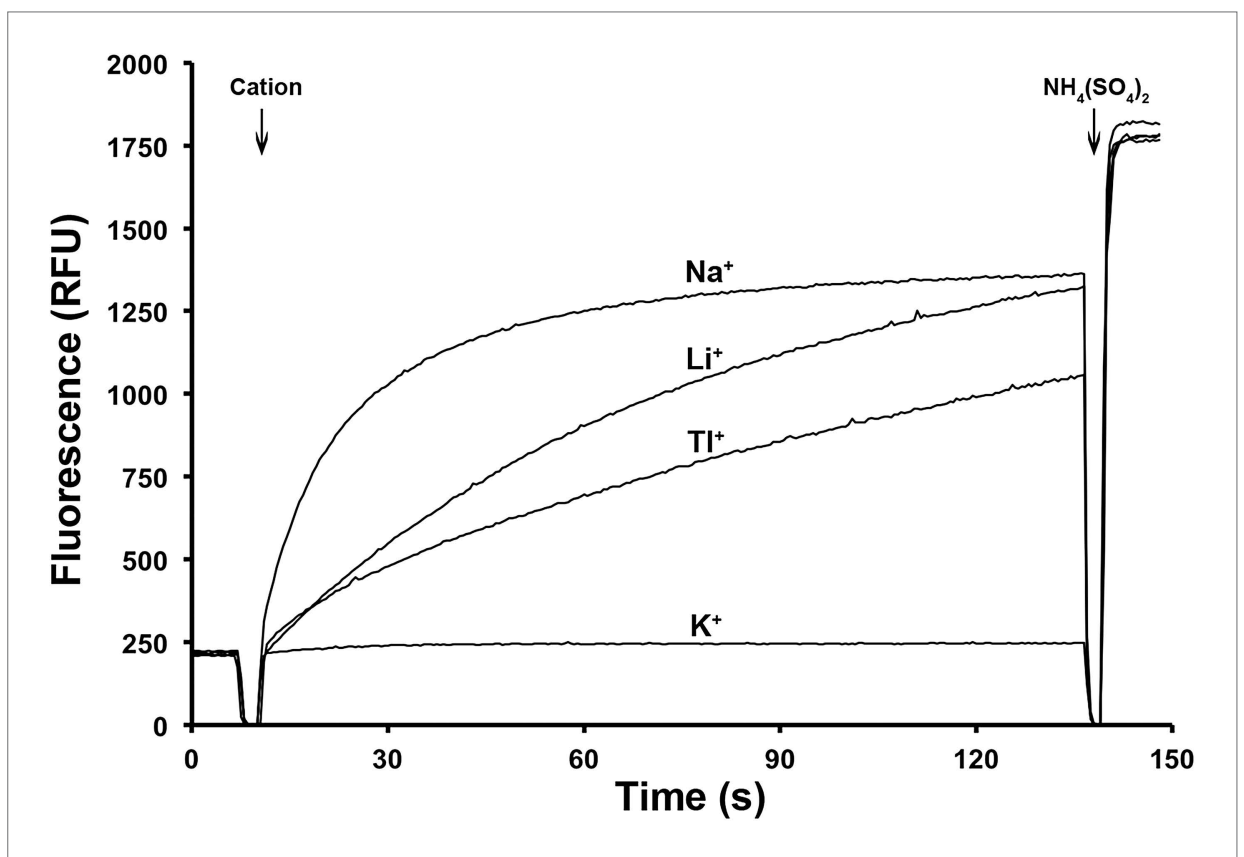

Figure 4. Ion selectivity of $\mathrm{PaNhaP}$. Ion selectivity was determined by acridine orange fluorescence at $\mathrm{pH}$ 6. $\mathrm{Na}^{+}$, $\mathrm{Li}^{+}, \mathrm{Tl}^{+}$are transported by $\mathrm{PaNhaP}, \mathrm{K}^{+}$is not. DOI: 10.7554/eLife.03579.013

and negatively charged (Figure 2-figure supplement 1), resulting in an increased $\mathrm{Na}^{+}$affinity. As a result, the transport rate would decrease, as the ions are bound more tightly. This is consistent with the increased transport rate of the E73A mutant, which has one less carboxyl in the binding site, hence releases $\mathrm{Na}^{+}$more easily (Figure $8 \mathrm{~B}$ ). In addition, the propagation of the $\mathrm{pH}$-induced conformational changes at the dimer interface via Glu73 or Tyr31 would modulate the binding site by changing the coordination geometry for the ions (Figure 5-figure supplement 1A, Figure 5-figure supplement 2). Future structure-based molecular dynamics simulations should show how the protonation state of each of these residues influence the affinity of the binding site for $\mathrm{Na}^{+}$in a $\mathrm{pH}$-dependent manner.

The $\mathrm{pH}$-dependent transport activity of PaNhaP suggests a self-regulatory mechanism for the binding site rather than regulation by a separate $\mathrm{pH}$ sensor as proposed for EcNhaA (Herz et al., 2010; Diab et al., 2011; Schushan et al., 2012). At the pH 5 activity maximum of PaNhaP, transport is not limited by $\mathrm{Na}^{+}$affinity. Under these conditions, substrate binding of the PaNhaP dimer is noncooperative, but unexpectedly it becomes cooperative at $\mathrm{pH}$ 6. Cooperative ion binding is most likely mediated by Glu73 and may be important for controlling the intracellular $\mathrm{pH}$ at neutral or basic $\mathrm{pH}$, where a cooperative increase in $\mathrm{Na}^{+}$affinity would gradually inhibit substrate release and slow down transport. This may be a safety mechanism to protect the organism against excessive influx of $\mathrm{Na}^{+}$, and hence efflux of protons, at rising $\mathrm{pH}$, which may be critical for survival.

The medically relevant but elusive human $\mathrm{Na}^{+} / \mathrm{H}^{+}$exchanger $\mathrm{NHE} 1$ is a dimer (Fafournoux et al., 1994) like PaNhaP. Several other common features, including high sequence homology (Goswami et al., 2011) especially of the unwound stretches in $\mathrm{H} 5$ and $\mathrm{H} 12$, key residues in the ion binding site such as Ser155, Asp130 and the ND motif, the functionally important Arg337 and Arg362 (Hellmer et al., 2003), as well as $\mathrm{pH}$ profiles and transport kinetics suggest that the archaeal and mammalian CPA1 antiporters (Fuster et al., 2008) work essentially in the same way. Remarkably, NHE1 also shows $\mathrm{pH}$-dependent $\mathrm{Na}^{+}$cooperativity, with a Hill coefficient of 1.8 at $\mathrm{pH} 6.8$ that drops to $\sim 1$ at $\mathrm{pH} 6$ (Fuster et al., 2008). The PaNhaP structure thus serves as an excellent model for the membrane part of NHE1. Molecular details of allosteric regulation in NHE1 are likely to be different, as the His292 that reorients in response to $\mathrm{pH}$ in $\mathrm{PaNhaP}$ is not conserved (Goswami et al., 2011).

The electrogenic CPA2 antiporters, such as EcNhaA or TtNapA, which exchange two protons against one $\mathrm{Na}^{+}$, have two conserved aspartates in place of the ND motif in $\mathrm{H} 6$. In terms of its overall 


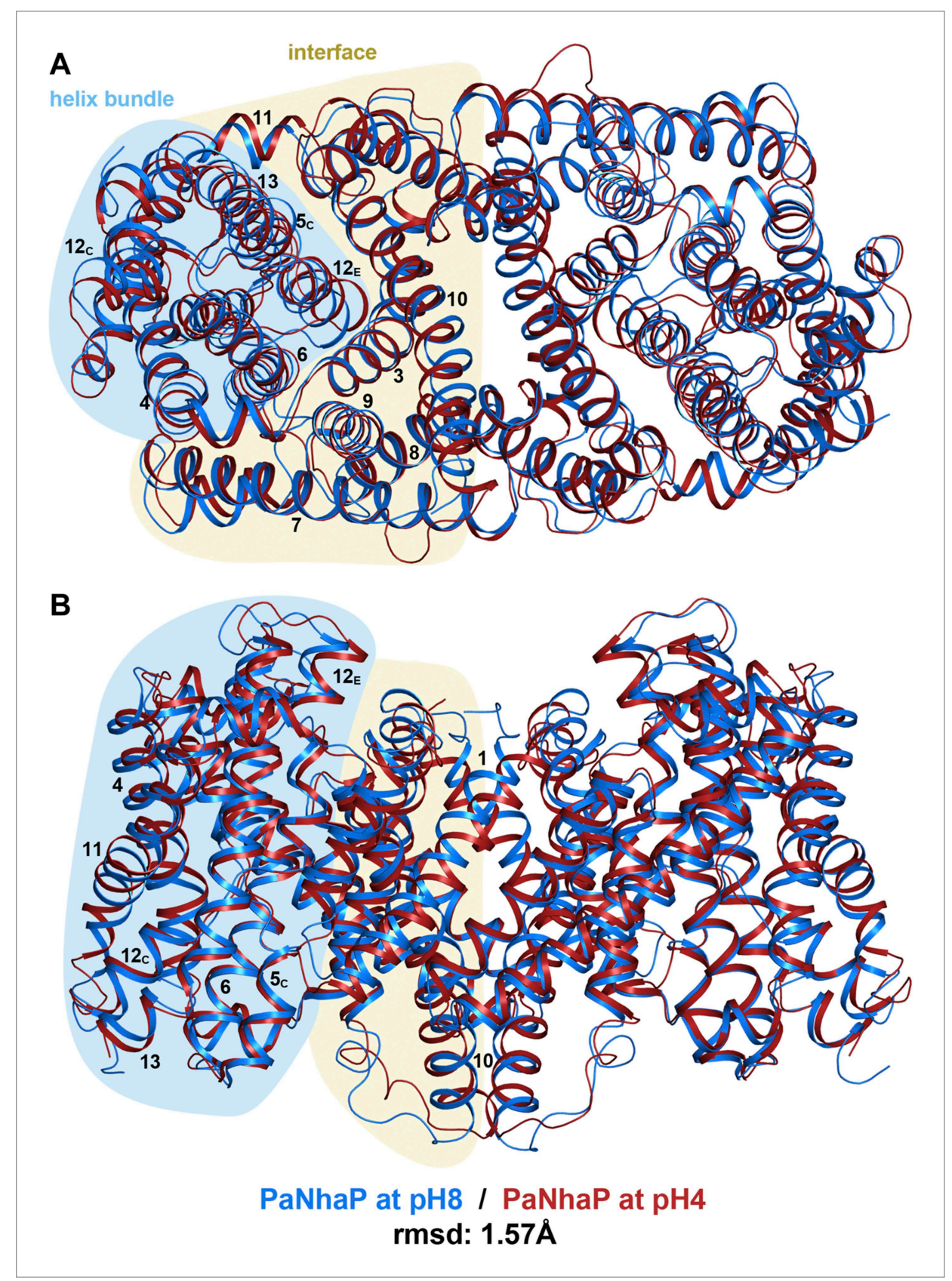

Figure 5. $\mathrm{pH}$-induced conformational changes in the PaNhaP dimer. (A) cytoplasmic view, (B) side view as in Figure 1. At pH 4 (red), helix $\mathrm{H} 4$ moves towards the cytoplasm by $1.5 \AA$. Within the 6-helix bundle, the extracellular ends of helix $\mathrm{H}_{\mathrm{E}}$ and $\mathrm{H} 6$ move towards $\mathrm{H} 12$ by $\sim 1.5 \AA$. Helix $\mathrm{H} 11$ and $\mathrm{H} 13$ tilt by about $2-3^{\circ}$ each, such that the cytoplasmic end of helix $\mathrm{H} 11$ moves towards $\mathrm{H}_{12}$, which shifts by a similar amount in the same direction. The extracellular end of helix $\mathrm{H} 12_{\mathrm{E}}$ moves towards helix $\mathrm{H} 3$ by $\sim 3 \AA$. The rmsd between the structures at $\mathrm{pH} 8$ and $\mathrm{pH} 4$ is $1.57 \AA$.

DOI: 10.7554/eLife.03579.014

The following figure supplements are available for figure 5:

Figure supplement 1. $\mathrm{pH}$-induced conformational changes at the dimer interface. DOI: 10.7554/eLife.03579.015

Figure supplement 2. $\mathrm{pH}$-induced conformational changes in the substrate binding site. DOI: 10.7554/eLife.03579.016

structure, TtNapA (Lee et al., 2013) is more similar to PaNhaP than to EcNhaA (Hunte et al., 2005), especially with respect to the dimer interface. The tertiary structure of the CPA antiporters is thus not a diagnostic of electroneutral or electrogenic transport. 


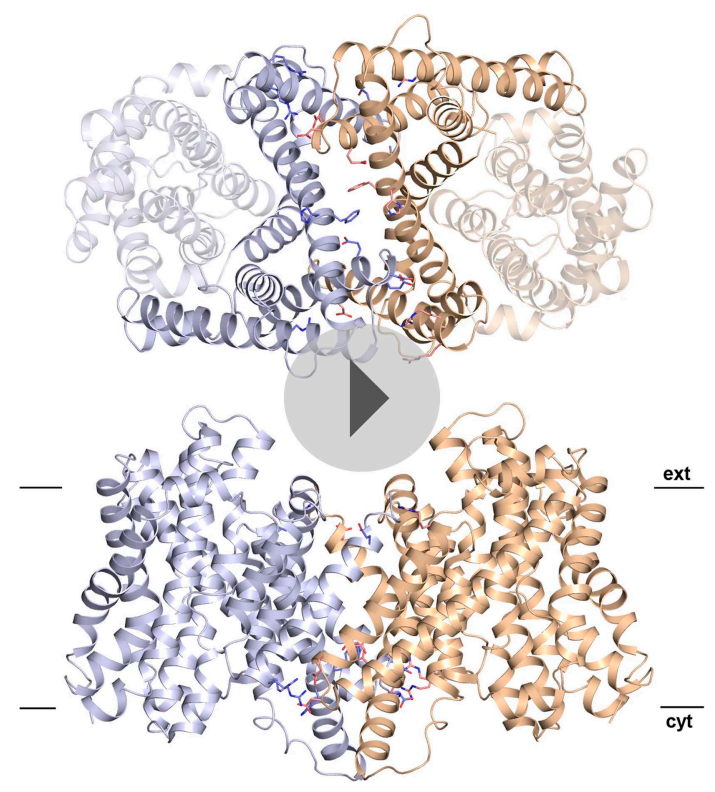

Video 2. $\mathrm{pH}$-induced conformational changes in PaNhaP. A morph between the $\mathrm{pH} 4$ and $\mathrm{pH} 8$ structures reveals only small changes in the 6-helix bundle, but significant rearrangements at the dimer interface. Six ion bridges that lock the two protomers together at $\mathrm{pH} 8$ break at $\mathrm{pH} 4$. As a result, the two protomers tilt away from each other at lower $\mathrm{pH}$. His292 has a pivotal role in the allosteric $\mathrm{pH}$-dependent side chains on the cytoplasmic side of the dimer interface repel one another by electrostatic repulsion, resulting in a $\sim 7 \AA$ movement that disrupts the hydrogen-bonding network with Glu233. DOI: 10.7554/eLife.03579.017 protomer interaction. At $\mathrm{pH} 4$, the protonated His292

\section{Mechanisms of ion binding and release}

In Pyrococcus, the $\mathrm{Na}^{+}$gradient required for ATP synthesis is maintained by specific antiporters (McTernan et al., 2014). We therefore assume that PaNhaP, like human NHE1, utilizes the $\mathrm{Na}^{+}$ gradient across the membrane (Cohen et al., 2003) for $\mathrm{pH}$ homeostasis. Protons, probably in the form of hydronium ions $\left(\mathrm{H}_{3} \mathrm{O}^{+}\right)$, can reach the binding pocket either through the cytoplasmic funnel or through the narrow polar channel (Figure 9). Only small rearrangements of the residues lining this channel would be required for $\mathrm{H}_{3} \mathrm{O}^{+}$to pass. Using the second narrow polar channel for proton translocation would physically separate the routes for $\mathrm{Na}^{+}$and $\mathrm{H}_{3} \mathrm{O}^{+}$on the cytoplasmic side, which may be an advantage as the two ion currents flow in opposite directions. It would also explain why residues that line this channel, in particular the Glu154/Arg337 ion bridge and Asn158, which do not participate in ion coordination, are so highly conserved in the family. Molecular dynamics simulations and functional analysis of suitable mutants will be required to differentiate between the two proton paths, which both appear equally likely on the basis of the $\mathrm{x}$-ray structures.

\section{Materials and methods}

\section{Cloning, expression and purification}

A codon-optimized synthetic gene for the $\mathrm{Na}^{+} / \mathrm{H}^{+}$antiporter from Pyrococcus abyssi (WP_010868413.1) was cloned into a vector with a C-terminal cysteine protease domain fusion as described previously for soluble proteins (Shen et al., 2009). Mutations were introduced by sitedirected mutagenesis (Braman et al., 1996). The resulting plasmids were used to transform $E$. coli C41-(DE3) cells. The protein was expressed for $10 \mathrm{hr}$ at $37^{\circ} \mathrm{C}$ in ZYM-5052 autoinduction medium (Studier, 2005).

Membranes were isolated from a $12 \mathrm{I}$ culture and resuspended at $15 \mathrm{mg} / \mathrm{ml}$ protein in $20 \mathrm{mM}$ Tris $\mathrm{pH} 7.4,250 \mathrm{mM}$ sucrose, $140 \mathrm{mM}$ choline chloride. The suspension was diluted 1:3 in solubilization buffer (20 mM Tris pH 7.4, $150 \mathrm{mM} \mathrm{NaCl}, 30 \%$ Glycerol and $1.5 \%$ Cymal-5). After solubilization overnight at $4^{\circ} \mathrm{C}$ the solution was clarified by centrifugation at $100,000 \times \mathrm{g}$ for $1 \mathrm{hr}$. The supernatant was supplemented with $5 \mathrm{mM}$ imidazole, incubated for $2 \mathrm{hr}$ with Talon resin (Clontech, Mountain View, CA) at $4^{\circ} \mathrm{C}$ and loaded on a Biorad column. Unspecifically bound proteins were eluted with washing buffer (20 mM Tris pH 7.4, $300 \mathrm{mM} \mathrm{NaCl}, 10 \mathrm{mM}$ imidazole and 0.15\% Cymal-5). PaNhaP was cleaved off the column by incubating the beads in elution buffer $(20 \mathrm{mM}$ Tris $\mathrm{pH} 7.4,300 \mathrm{mM} \mathrm{NaCl}, 0.15 \%$ Cymal-5, $20 \mu \mathrm{M}$ inositol-hexaphosphate) for $30 \mathrm{~min}$. The eluted protein was concentrated to $5 \mathrm{mg} / \mathrm{ml}$ using a concentrator with $50 \mathrm{kDa}$ cutoff and applied to a Superdex 200 size exclusion column equilibrated with $10 \mathrm{mM} \mathrm{Na}$-Citrate $\mathrm{pH}$ 4.0, $300 \mathrm{mM} \mathrm{NaCl}$ and $0.15 \%$ Cymal-5. Antiporter-containing fractions were pooled and concentrated to $5 \mathrm{mg} / \mathrm{ml}$. The concentrated protein solution was diluted 1:4 with the same buffer containing $100 \mathrm{mM} \mathrm{NaCl}$ and re-concentrated as above. Selenomethionine (SeMet) labeled protein was expressed in PASM-5052 autoinduction medium (Studier, 2005) and purified as described for the native protein in the presence of $5 \mathrm{mM} \beta$-mercaptoethanol throughout all purification steps. $\beta$-mercaptoethanol was exchanged to $1 \mathrm{mM}$ TCEP (Tris-(2-carboxyethyl) phosphine) in the final size-exclusion chromatography step. 


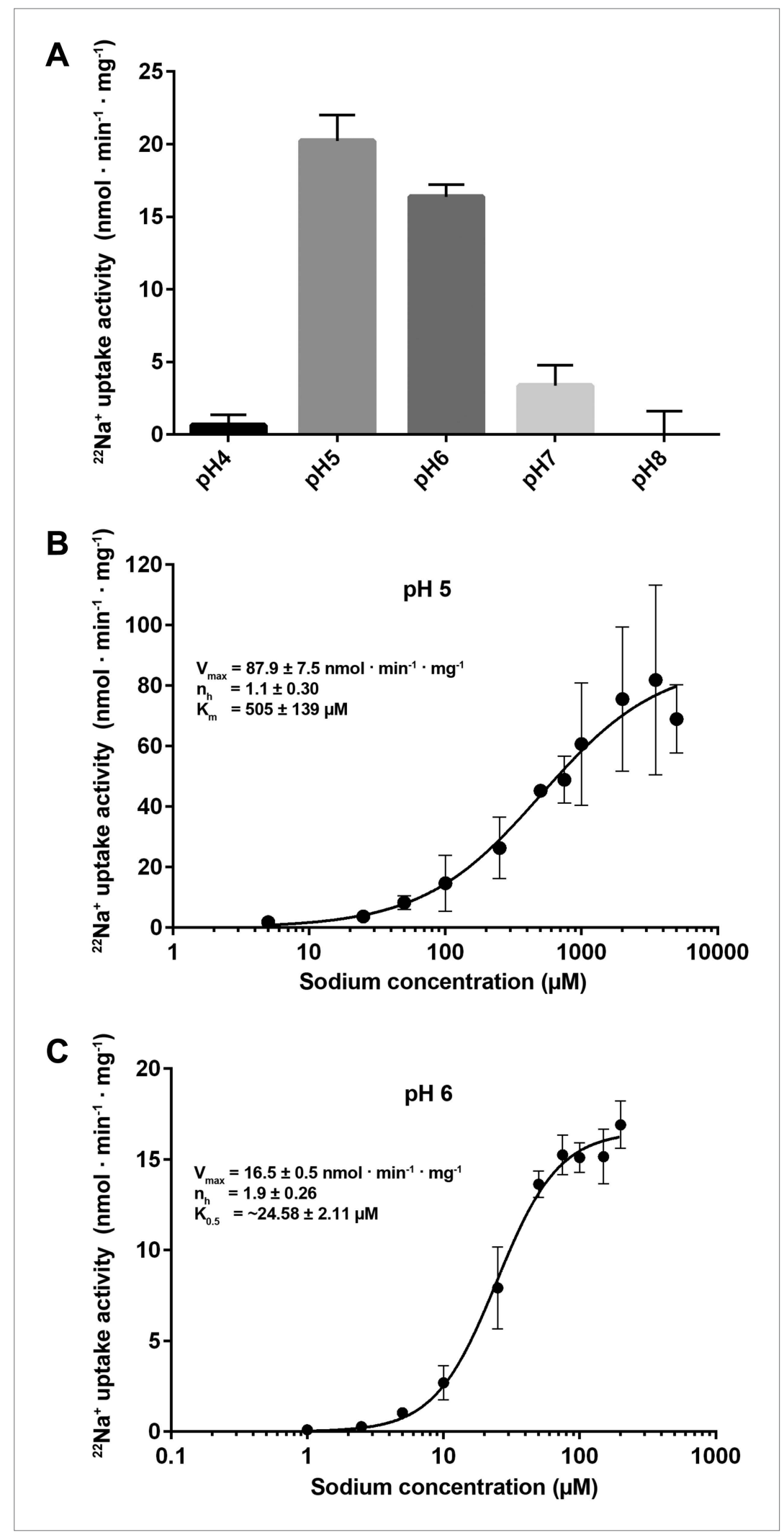

Figure 6. Transport activity of $\mathrm{PaNhaP}$. (A) $\mathrm{pH}$ dependence of transport activity determined by ${ }^{22} \mathrm{Na}^{+}$uptake with inside-acidic PaNhaP proteoliposomes. The antiporter is active at $\mathrm{pH} 5$ and $\mathrm{pH}$ 6; at $\mathrm{pH} 4$ and $\mathrm{pH} 7$ transport drops to background level. (B) Concentration-dependent ${ }^{22} \mathrm{Na}^{+}$-uptake by inside-acidic PaNhaP proteoliposomes at pH 5 Figure 6. Continued on next page 
Figure 6. Continued

gives a $v_{\max }$ of $87.9 \pm 7.5 \mathrm{nmol} \cdot \mathrm{min}^{-1} \cdot \mathrm{mg}^{-1}$ at room temperature, indicating a transport rate of $4.4 \mathrm{Na}^{+}$ions per protomer per minute. At pH 5 the Hill coefficient $\left(n_{h}\right)$ is $1.1 \pm 0.30$, indicating non-cooperative transport. (C) At pH 6, transport is cooperative, with a Hill coefficient of $1.9 \pm 0.26$, indicating allosteric coupling of the two ion-binding sites in the dimer. $v_{\max }$ at room temperature decreases to $16.5 \pm 0.5 \mathrm{nmol} \cdot \mathrm{min}^{-1} \cdot \mathrm{mg}^{-1}$.

DOI: 10.7554/eLife.03579.018

The following figure supplements are available for figure 6:

Figure supplement 1. Sodium efflux measurements.

DOI: 10.7554/eLife.03579.019

Figure supplement 2. Eadie-Hofstee plots.

DOI: 10.7554/eLife.03579.020

\section{Reconstitution}

E. coli polar lipids (EPL, Avanti Polar Lipids, Inc., Alabaster, AL) were dried under nitrogen and resuspended in reconstitution buffer. Unilamellar vesicles were prepared by extruding the resuspended lipids using an extruder (Avestin, Inc., Canada) with $400 \mathrm{~nm}$ polycarbonate filters. Vesicles were destabilized by stepwise addition of n-octyl- $\beta-D$-glucoside (OG). The process was monitored at $540 \mathrm{~nm}$. Addition of OG was stopped at around $1 \%$ final concentration when the absorbance decreased rapidly. Protein was added to the destabilized liposomes at a lipid-to-protein ratio (LPR) of 100:1 and incubated for $1 \mathrm{hr}$ at room temperature. The solution was dialyzed (14 kDa cutoff) overnight at room temperature against detergent-free reconstitution buffer. Biobeads (SM2, Biorad, Hercules, CA) were added to the dialysis buffer to ensure complete removal of the detergent. Proteoliposomes were centrifuged at 300,000×g for 20 min and washed once with reconstitution buffer. Washed proteoliposomes were pelleted again and resuspended at $\sim 60 \mathrm{mg} / \mathrm{ml}$ lipid in reconstitution buffer for further use.

\section{Fluorescence assays}

$\mathrm{PaNhaP}$ was reconstituted into proteoliposomes in $10 \mathrm{mM}$ choline citrate/Tris $\mathrm{pH} 6-8,200 \mathrm{mM} \mathrm{NaCl}$ and $5 \mathrm{mM} \mathrm{KCl}$. To start the reaction $2 \mu \mathrm{l}$ of proteoliposome suspension were diluted into $2 \mathrm{ml}$ reaction buffer (10 mM choline-citrate/Tris at same pH, $5 \mathrm{mM} \mathrm{KCl}, 2 \mu \mathrm{M}$ acridine orange). Emission of acridine orange (excitation: $495 \mathrm{~nm}$ ) was monitored at $530 \mathrm{~nm}$. To determine ion selectivity $5 \mathrm{mM} \mathrm{NaAc}$, LiAc, KAc or TIAc were added to the reaction mixture after the initial sodium efflux reached equilibrium. Addition of substrates for $\mathrm{PaNhaP}$ to the reaction buffer results in proton efflux and fluorescence dequenching. Finally, the remaining proton gradient was dissipated by adding $25 \mathrm{mM}\left(\mathrm{NH}_{4}\right)_{2} \mathrm{SO}_{4}$ in all experiments as a control. Electrogenic transport was investigated by addition of $100 \mathrm{nM}$ valinomycin to the reaction buffer. The temperature was kept constant in a water bath during each experiment. Temperature dependence of transport was measured (triplicates) between $20^{\circ} \mathrm{C}$ and $45^{\circ} \mathrm{C}$ by correlating the speed of fluorescence quenching in the mid of the curve drop.

\section{Radioactive ${ }^{22} \mathrm{Na}^{+}$uptake assays}

$\mathrm{PaNhaP}$ was reconstituted in $20 \mathrm{mM}$ choline citrate/Tris $\mathrm{pH} 4-8,10 \mathrm{mM}\left(\mathrm{NH}_{4}\right)_{2} \mathrm{SO}_{4}$. The reaction mixture contained $20 \mathrm{mM}$ of the same buffer, $10 \mathrm{mM}$ choline chloride, $1 \mu \mathrm{Ci} / \mathrm{ml}^{22} \mathrm{Na}^{+}$and $\mathrm{NaCl}$ concentrations ranging from $1 \mu \mathrm{M}$ to $5 \mathrm{mM}$. The $\mathrm{pH}$-profile was determined at $200 \mu \mathrm{M} \mathrm{NaCl}$. For each reaction $2 \mu \mathrm{l}$ proteoliposomes were diluted in $200 \mu \mathrm{l}$ reaction buffer to initiate the reaction. The addition of proteoliposomes to the reaction buffer results in $\mathrm{NH}_{3}$ efflux, producing an outward-directed proton gradient (Dibrov and Taglicht, 1993). At the time points indicated, $200 \mu$ samples of the reaction mixture were applied to a $0.2 \mu \mathrm{m}$ millipore nitrocellulose (Millipore, Billerica, MA) filter and washed with $3 \mathrm{ml}^{22} \mathrm{Na}^{+}$-free reaction buffer. Filters were transferred to counting tubes and $4 \mathrm{ml}$ liquid scintillation cocktail (Rotiszint, Germany) was added. All measurements were performed at room temperature and repeated at least three times.

\section{Crystallization}

Prior to crystallization, the buffer for native protein was exchanged in the final concentrating step to $10 \mathrm{mM}$ Tris/ $\mathrm{HCl} \mathrm{pH} \mathrm{7.4,100} \mathrm{mM} \mathrm{NaCl}, 0.15 \%$ Cymal-5. Crystallization was performed in 24-well plates in hanging drops at $18^{\circ} \mathrm{C}$. SeMet protein was supplemented with $1 \% \mathrm{OG}$ and native protein with $1 \%$ n-octyl- $\beta$-thio-maltoside (OTM). The protein solutions were mixed 1:1 with reservoir buffer (native protein: $40 \mathrm{mM} \mathrm{Na}$-Citrate $\mathrm{pH}$ 4.0, $100 \mathrm{mM} \mathrm{NaCl}$, 28-33 \% PEG 350 MME; SeMet protein: 100 mM 


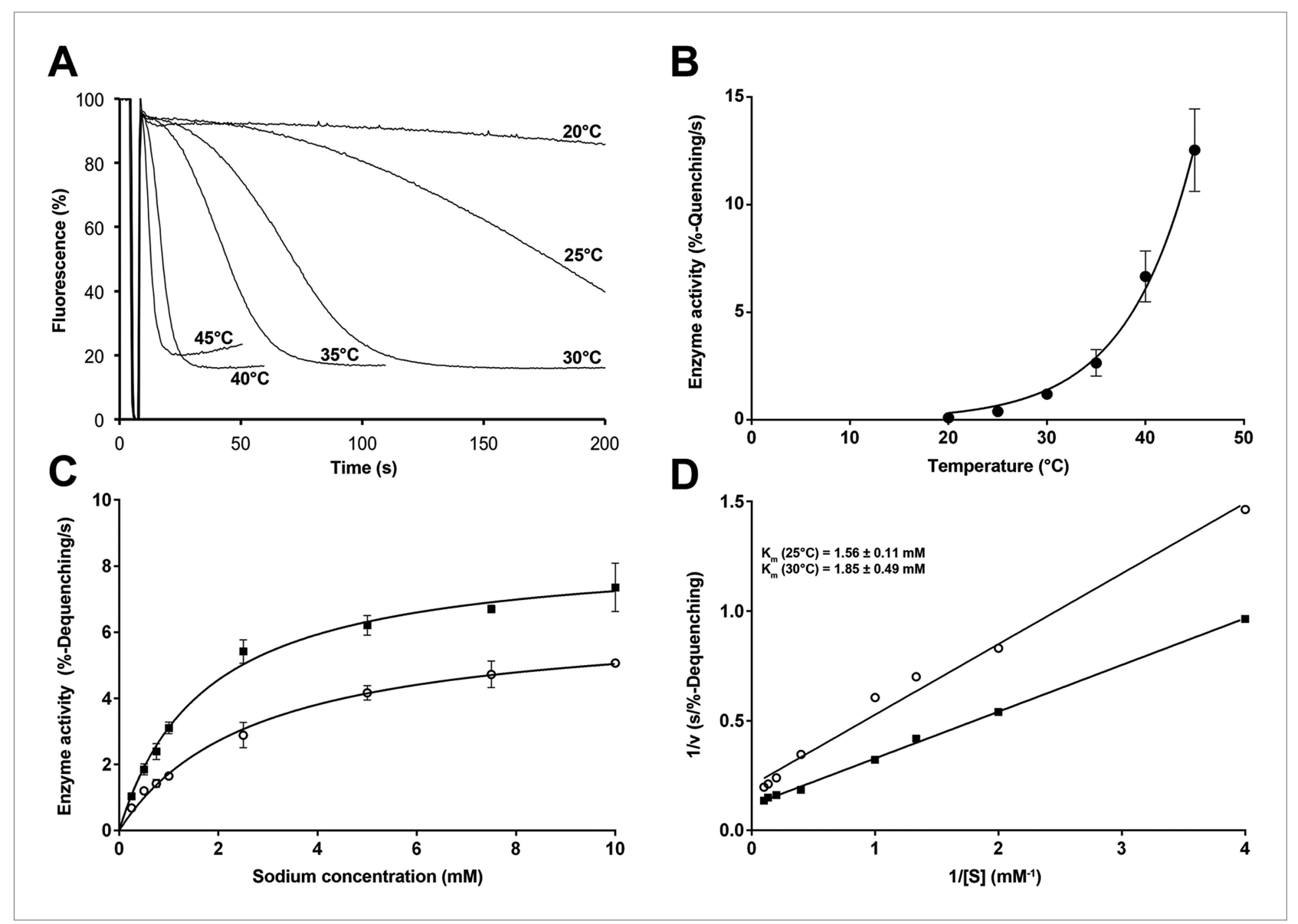

Figure 7. Temperature dependence of $\mathrm{PaNhaP}$. (A, B) At pH 6 transport activity increases by a factor of 2.1 for every $5^{\circ} \mathrm{C}$ rise in temperature, as measured by sodium efflux under symmetrical $\mathrm{pH}$. The slight rise in fluorescence towards longer times at $40^{\circ} \mathrm{C}$ and above in $\mathrm{A}$ is due to increasing proton leakage of the proteoliposomes. (C, D) Effect of temperature on substrate affinity at $25^{\circ} \mathrm{C}$ (empty dots) and $30^{\circ} \mathrm{C}$ (filled squares) measured by $\Delta \mathrm{pH}$-driven sodium uptake in proteoliposomes using Acridine orange fluorescence. In contrast to $\mathrm{V}_{\max } \mathrm{K}_{\mathrm{m}}$ does not change much with increasing temperature $\left(1.56 \pm 0.11 \mathrm{mM}\right.$ at $25^{\circ} \mathrm{C} ; 1.85 \pm 0.49 \mathrm{mM}$ at $\left.30^{\circ} \mathrm{C}\right)$.

Tris/ $\mathrm{HCl}$ pH 8.0, $100 \mathrm{mM} \mathrm{CaCl} / \mathrm{MgCl}_{2}, 35-40 \%$ PEG 400). Trapezoidal pH 4 crystals grew up to $200 \mu \mathrm{m}$ within 7 days. At pH 8, long needle-like crystals grew to full size within 3 months. Crystals were vitrified directly in liquid nitrogen for data collection. For thallium soaks, crystals grown at $\mathrm{pH} 8$ were transferred into a buffer containing $100 \mathrm{mM}$ Tris/acetate, $100 \mathrm{mM} \mathrm{MgAc}_{2}, 40 \%$ PEG 400, $2 \mathrm{mM}$ K-citrate, $0.15 \%$ Cymal-5 and $1 \%$ OG. After five minutes the crystals were transferred to another drop of the same solution containing $25 \mathrm{mM}$ TIAc. Crystals were incubated overnight and vitrified directly in liquid nitrogen.

\section{Data collection, processing and structure determination}

All diffraction data were collected with crystals kept at $100 \mathrm{~K}$ at the beamline X10SA of the Swiss Light Source in Villigen, Switzerland. Datasets were processed with XDS (Kabsch, 1993) and scaled with AIMLESS in the CCP4 package (Collaborative Computational Project 4, 1994). Resolution cut-offs were chosen based on CC1/2 (cross correlation of half datasets), completeness and $I / \sigma(I)$-values in high resolution shells (Karplus and Diederichs, 2012). Coot (Emsley and Cowtan, 2004) was used for model building and the PHENIX package (Adams et alo, 2004) for refinement. Phases were obtained by single-wavelength anomalous dispersion (SAD) using SeMet crystals. Datasets from two crystals were merged to achieve a high multiplicity and to increase the anomalous signal (Liu et al., 2011). The Selenium substructure containing 11 out of 14 possible positions was determined at $5.7 \AA$ using SHELXD (Sheldrick, 2010).

Phasing, hand determination, density modification with Parrot (Zhang et al., 1997) and initial model building with Buccaneer (Cowtan, 2006) was performed with a beta version of CRANK2 


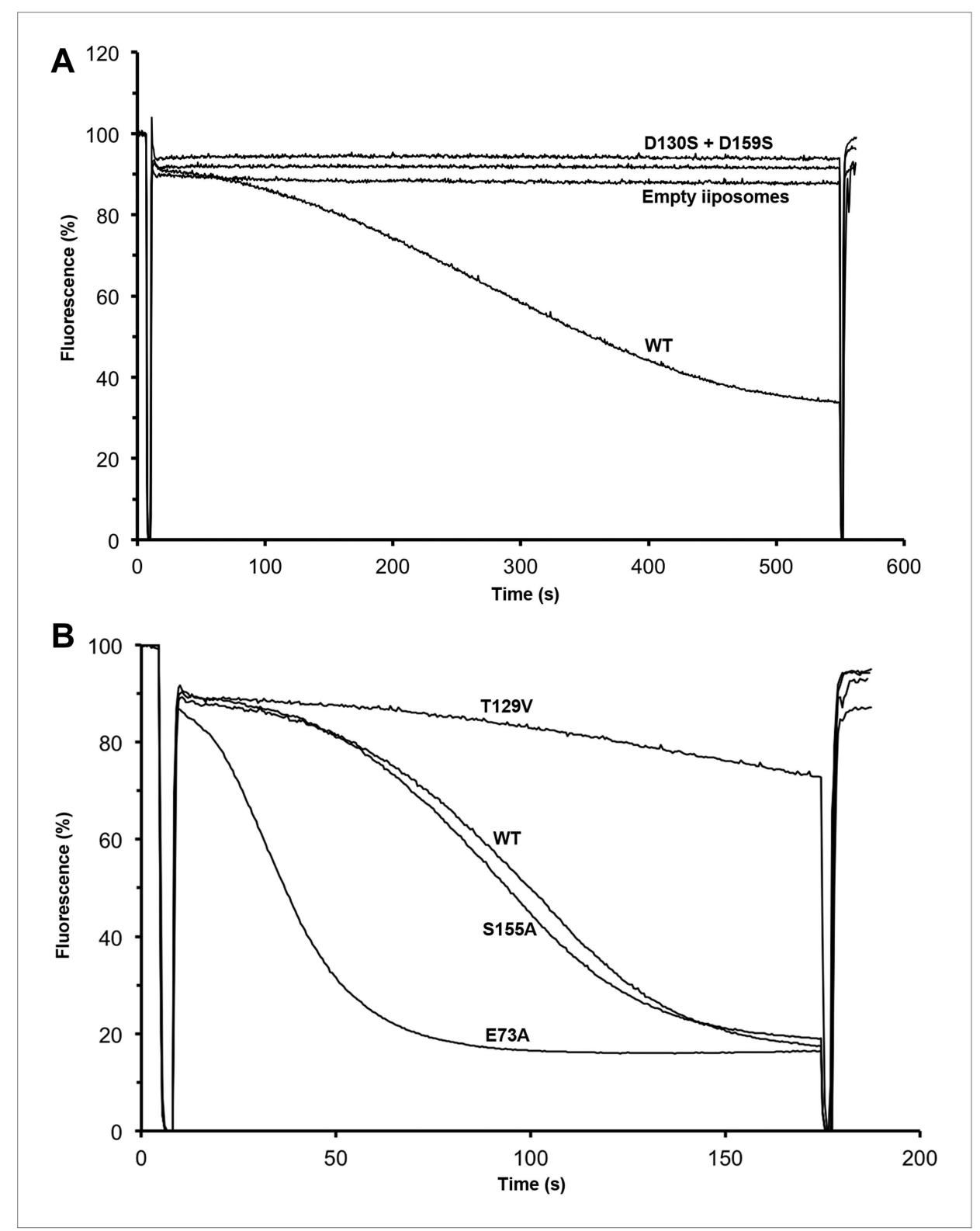

Figure 8. Transport activity of binding site mutants. Sodium efflux from proteoliposomes at $\mathrm{pH} 6$ was measured to investigate PaNhaP mutants. Antiport activity establishes a $\Delta \mathrm{pH}$ across the membrane, which results in acridine orange fluorescence quenching. (A) Mutation of Asp130 or Asp159 to serine abolishes transport activity. (B) Replacement of Thr129 by valine, as in eukaryotic antiporters, reduces the transport activity. Replacement of Glu73 by alanine increases activity significantly, whereas exchanging Ser155 against alanine has no effect compared to wildtype.

DOI: 10.7554/eLife.03579.022

The following figure supplement is available for figure 8 :

Figure supplement 1. Interface crosslinks. DOI: 10.7554/eLife.03579.023

(Pannu et al., 2011). The resulting electron density map was used for manual building of an initial backbone model. Selenium positions were used to assign side chains in initial refinement rounds. Molecular replacement was performed using PHASER (McCoy, 2007) with the assigned dimer model to extend the resolution to $3.15 \AA$. The final pH 8 model was used for molecular replacement to phase the $\mathrm{pH} 4$ structure and the thallium bound structure at $\mathrm{pH}$ 8. Superimpositions were performed using secondary structure superimposition (Krissinel and Henrick, 2004) within Coot (Emsley and Cowtan, 2004). 


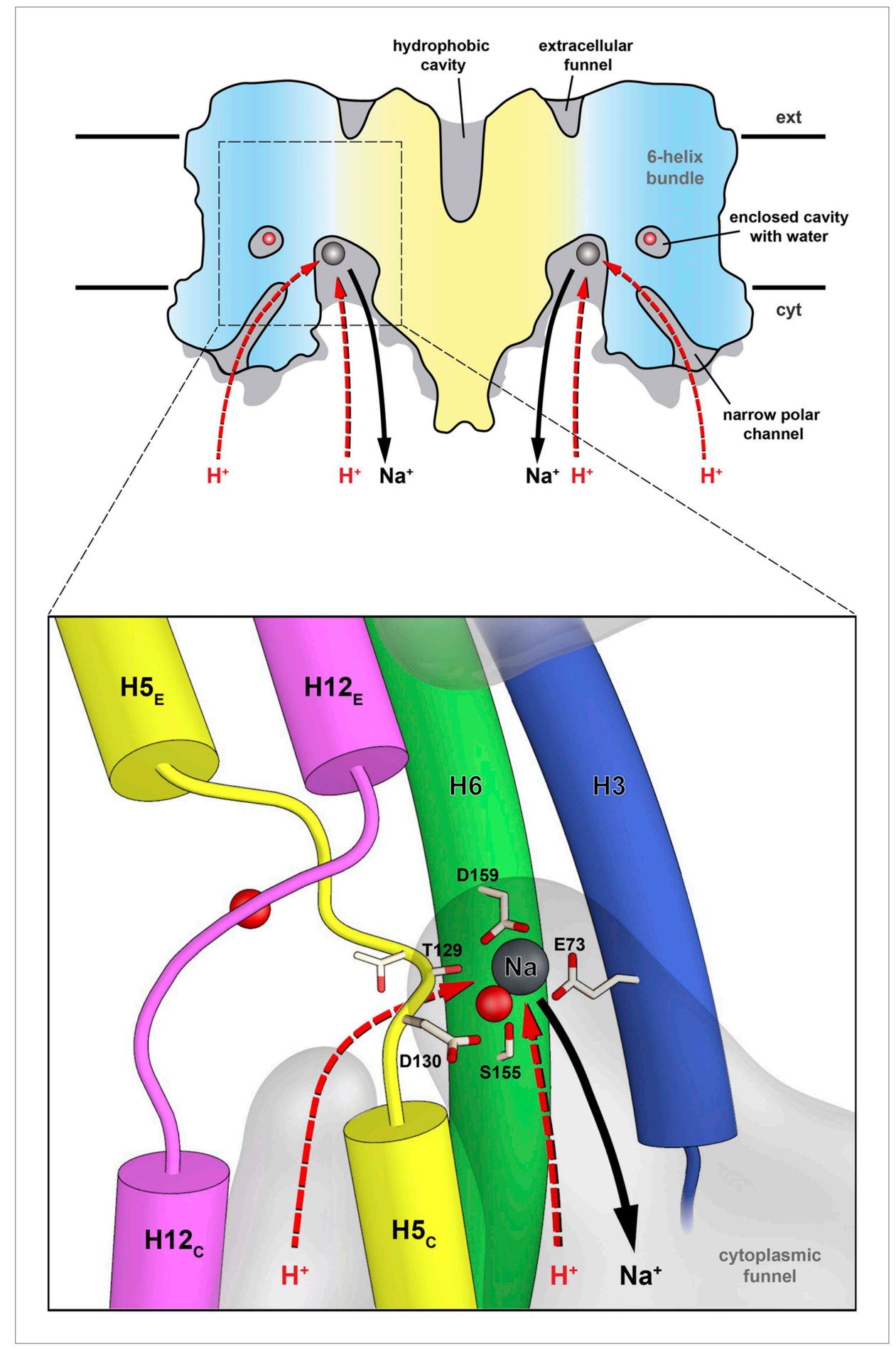

Figure 9. Substrate ion exchange on the cytoplasmic side. The substrate-binding site of PaNhaP is located between the unwound stretches in the six-helix-bundle and the interface domain. The substrate ion is bound by acidic sidechains and polar groups in the bundle helices $\mathrm{H} 5$ and $\mathrm{H} 6$, and a glutamate in the interface helix $\mathrm{H} 3$ at the deepest point of the cytoplasmic funnel. While the funnel extends between the six-helix bundle and the dimer interface, the narrow polar channel is defined by the bundle helices $\mathrm{H} 5_{\mathrm{C}}, \mathrm{H} 12_{\mathrm{C}}, \mathrm{H} 6$ and $\mathrm{H} 13$. Protons may approach the binding site either through the cytoplasmic funnel, or through the narrow polar channel (red arrows). A proton displaces the bound substrate ion, which escapes to the cytoplasm (black arrow). Employing the narrow polar channel as the proton path would separate the $\mathrm{Na}^{+}$ion and proton currents on the cytoplasmic side, which may be advantageous at high transport rates.

DOI: 10.7554/eLife.03579.024 
Figures were prepared with PyMOL (DeLano and Lam, 2005). The potential surface was calculated with pdb2pqr (Dolinsky et al., 2007) and APBS (Baker et al., 2001). Analysis of transport pathways, channels and cavities was performed with Hollow (Ho and Gruswitz, 2008) and visualized within PyMOL.

\section{Author information}

Atomic coordinates and structure factors have been deposited with the PDB under accession codes: $4 \mathrm{cz} 8$ for the $\mathrm{pH} 8$ SeMet structure, $4 \mathrm{cz} 9$ for the $\mathrm{pH} 4$ structure and $4 \mathrm{cza}$ for the thallium-bound structure at $\mathrm{pH} 8$.

\section{Acknowledgements}

We thank Sabine Häder for technical assistance, Cristina Paulino, Gerhard Hummer, Klaus Fendler and Christine Ziegler for discussion, and Pavol Skubak for the beta version of the Crank2 software. Crystals were screened at the beamlines id23.1 and id29 of the European Synchrotron Radiation Facility (ESRF)/Grenoble and data were collected at the Max Planck beamline PXII of the Swiss Light Source (SLS). This work was funded by the Max Planck Society; the Frankfurt Cluster of Excellence Macromolecular Complexes; the Frankfurt International Max Planck Research School; and SFB 807 'Transport and communication across biological membranes'.

\section{Additional information}

Competing interests

WK: Reviewing editor, eLife. The other authors declare that no competing interests exist.

Funding

\begin{tabular}{|c|c|c|}
\hline Funder & Grant reference number & Author \\
\hline $\begin{array}{l}\text { Max-Planck-Gesellschaft } \\
\text { (Max Planck Society) }\end{array}$ & & $\begin{array}{l}\text { David Wöhlert, } \\
\text { Werner Kühlbrandt, } \\
\text { Özkan Yildiz }\end{array}$ \\
\hline $\begin{array}{l}\text { Deutsche } \\
\text { Forschungsgemeinschaft }\end{array}$ & $\begin{array}{l}\text { Cluster of Excellence, } \\
\text { Macromolecular Complexes }\end{array}$ & Werner Kühlbrandt \\
\hline $\begin{array}{l}\text { Max-Planck-Gesellschaft } \\
\text { (Max Planck Society) }\end{array}$ & $\begin{array}{l}\text { International Max Planck } \\
\text { Research School, Frankfurt }\end{array}$ & $\begin{array}{l}\text { David Wöhlert, } \\
\text { Werner Kühlbrandt }\end{array}$ \\
\hline $\begin{array}{l}\text { Deutsche } \\
\text { Forschungsgemeinschaft }\end{array}$ & $\begin{array}{l}\text { Transport and communication } \\
\text { across biological membranes } \\
\text { SFP807 }\end{array}$ & $\begin{array}{l}\text { David Wöhlert, } \\
\text { Werner Kühlbrandt }\end{array}$ \\
\hline
\end{tabular}

The funders had no role in study design, data collection and interpretation, or the decision to submit the work for publication.

Author contributions

DW, Purified and crystallized the protein, Performed the functional analyses; WK, Conception and design, Analysis and interpretation of data, Drafting or revising the article; ÖY, Conception and design, Acquisition of data, Analysis and interpretation of data, Drafting or revising the article

\section{Additional files}

Major datasets

The following datasets were generated:

\begin{tabular}{|c|c|c|c|c|}
\hline Author(s) & Year & Dataset title & Dataset ID and/or URL & $\begin{array}{l}\text { Database, license, } \\
\text { and accessibility } \\
\text { information }\end{array}$ \\
\hline $\begin{array}{l}\text { Woehlert D, Kuhlbrandt W, } \\
\text { Yildiz } \bigcirc\end{array}$ & 2014 & $\begin{array}{l}\text { Structure of the sodium } \\
\text { proton antiporter PaNhaP } \\
\text { from Pyrococcus abyssii }\end{array}$ & $\begin{array}{l}\text { http://www.pdb.org/pdb/ } \\
\text { search/structidSearch. } \\
\text { do?structureld=4CZ8 }\end{array}$ & $\begin{array}{l}\text { Publicly available } \\
\text { from RCSB Protein } \\
\text { Data Bank. }\end{array}$ \\
\hline
\end{tabular}




$\begin{array}{lllll}\begin{array}{l}\text { Woehlert D, Kuhlbrandt W, 2014 } \\ \text { Yildiz O }\end{array} & \begin{array}{l}\text { Structure of the sodium } \\ \text { proton antiporter PaNhaP } \\ \text { from Pyrococcus abyssii } \\ \text { at pH 4 }\end{array} & \begin{array}{l}\text { http://www.pdb.org/pdb/ } \\ \text { search/structidSearch. } \\ \text { do?structureld=4CZ9 }\end{array} & \begin{array}{l}\text { Publicly available } \\ \text { from RCSB Protein } \\ \text { Data Bank. }\end{array} \\ \begin{array}{l}\text { Woehlert D, Kuhlbrandt W, 2014 } \\ \text { Yildiz O }\end{array} & \begin{array}{l}\text { Structure of the sodium } \\ \text { proton antiporter PaNhaP } \\ \text { from Pyrococcus abysii }\end{array} & \begin{array}{l}\text { http://www.pdb.org/pdb/ } \\ \text { search/structidSearch. } \\ \text { do?structureld=4CZA }\end{array} & \begin{array}{l}\text { Publicly available } \\ \text { from RCSB Protein } \\ \text { Data Bank. }\end{array}\end{array}$

\section{References}

Adams PD, Gopal K, Grosse-Kunstleve RW, Hung LW, loerger TR, McCoy AJ, Moriarty NW, Pai RK, Read RJ, Romo TD, Sacchettini JC, Sauter NK, Storoni LC, Terwilliger TC. 2004. Recent developments in the PHENIX software for automated crystallographic structure determination. Journal of Synchrotron Radiation 11:53-55. doi: 10.1107/S0909049503024130.

Baker NA, Sept D, Joseph S, Holst MJ, McCammon JA. 2001. Electrostatics of nanosystems: application to microtubules and the ribosome. Proceedings of the National Academy of Sciences of USA 98:10037-10041. doi: 10.1073/pnas.181342398.

Boudker O, Ryan RM, Yernool D, Shimamoto K, Gouaux E. 2007. Coupling substrate and ion binding to extracellular gate of a sodium-dependent aspartate transporter. Nature 445:387-393. doi: 10.1038/ nature05455.

Braman J, Papworth C, Greener A. 1996. Site-directed mutagenesis using double-stranded plasmid DNA templates. Methods in Molecular Biology 57:31-44.

Brett CL, Donowitz M, Rao R. 2005. Evolutionary origins of eukaryotic sodium/proton exchangers. American Journal of Physiology Cell Physiology 288:C223-C239. doi: 10.1152/ajpcell.00360.2004.

Calinescu O, Paulino C, Kuhlbrandt W, Fendler K. 2014. Keeping it simple - transport mechanism and pH regulation in $\mathrm{Na}+/ \mathrm{H}+$ exchangers. The Journal of Biological Chemistry 289:13168-13176.

Cohen GN, Barbe V, Flament D, Galperin M, Heilig R, Lecompte O, Poch O, Prieur D, Querellou J, Ripp R, Thierry JC, Van der Oost J, Weissenbach J, Zivanovic Y, Forterre P. 2003. An integrated analysis of the genome of the hyperthermophilic archaeon Pyrococcus abyssi. Molecular Microbiology 47:1495-1512. doi: 10.1046/ j.1365-2958.2003.03381.x.

Collaborative Computational Project 4. 1994. The CCP4 suite: programs for protein crystallography. Acta Crystallographica Section D Biological Crystallography 50:760-763.

Cotton FA, Wilkinson G. 1988. Advanced Inorganic Chemistry, 5th edition New York: Wiley.

Cowtan K. 2006. The Buccaneer software for automated model building. 1. Tracing protein chains. Acta Crystallographica Section D Biological Crystallography 62:1002-1011. doi: 10.1107/S0907444906022116.

DeLano WL, Lam JW. 2005. PyMOL: A communications tool for computational models. Abstracts of Papers of the American Chemical Society 230:U1371-U1372.

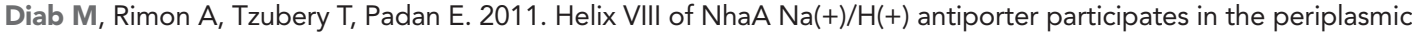
cation passage and $\mathrm{pH}$ regulation of the antiporter. Journal of Molecular Biology 413:604-614. doi: 10.1016/j. jmb.2011.08.046.

Dibrov PA, Taglicht D. 1993. Mechanism of $\mathrm{Na}+/ \mathrm{H}+$ exchange by Escherichia coli NhaA in reconstituted proteoliposomes. FEBS Letters 336:525-529. doi: 10.1016/0014-5793(93)80869-V.

Dolinsky TJ, Czodrowski P, Li H, Nielsen JE, Jensen JH, Klebe G, Baker NA. 2007. PDB2PQR: expanding and upgrading automated preparation of biomolecular structures for molecular simulations. Nucleic Acids Research 35:W522-W525. doi: 10.1093/nar/gkm276.

Emsley P, Cowtan K. 2004. Coot: model-building tools for molecular graphics. Acta Crystallographica Section D Biological Crystallography 60:2126-2132. doi: 10.1107/S0907444904019158.

Fafournoux P, Noel J, Pouyssegur J. 1994. Evidence that Na+/H+ exchanger isoforms NHE1 and NHE3 exist as stable dimers in membranes with a high degree of specificity for homodimers. The Journal of Biological Chemistry 269:2589-2596.

Fuster D, Moe OW, Hilgemann DW. 2008. Steady-state function of the ubiquitous mammalian Na/H exchanger (NHE1) in relation to dimer coupling models with $2 \mathrm{Na} / 2 \mathrm{H}$ stoichiometry. The Journal of General Physiology 132:465-480.

Goswami P, Paulino C, Hizlan D, Vonck J, Yildiz O, Kuhlbrandt W. 2011. Structure of the archaeal Na+/H+ antiporter NhaP1 and functional role of transmembrane helix 1. The EMBO Journal 30:439-449. doi: 10.1038/ emboj.2010.321.

Harding MM. 2002. Metal-ligand geometry relevant to proteins and in proteins: sodium and potassium. Acta Crystallographica Section D Biological Crystallography 58:872-874. doi: 10.1107/S0907444902003712.

Hellmer J, Teubner A, Zeilinger C. 2003. Conserved arginine and aspartate residues are critical for function of MjNhaP1, a Na+/H+ antiporter of M. jannaschii. FEBS Letters 542:32-36. doi: 10.1016/S0014-5793(03)00332-6.

Herz K, Rimon A, Olkhova E, Kozachkov L, Padan E. 2010. Transmembrane segment II of NhaA Na+/H+ antiporter lines the cation passage, and Asp65 is critical for $\mathrm{pH}$ activation of the antiporter. The Journal of Biological Chemistry 285:2211-2220. doi: 10.1074/jbc.M109.047134.

Ho BK, Gruswitz F. 2008. HOLLOW: generating accurate representations of channel and interior surfaces in molecular structures. BMC Structural Biology 8:49. 
Hunte C, Screpanti E, Venturi M, Rimon A, Padan E, Michel H. 2005. Structure of a $\mathrm{Na}+/ \mathrm{H}+$ antiporter and insights into mechanism of action and regulation by pH. Nature 435:1197-1202. doi: 10.1038/nature03692.

Kabsch W. 1993. Automatic processing of rotation diffraction data from crystals of initially unknown symmetry and cell constants. Journal of Applied Crystallography 26:795-800. doi: 10.1107/S0021889893005588.

Kalayil S, Schulze S, Kuhlbrandt W. 2013. Arginine oscillation explains $\mathrm{Na}+$ independence in the substrate/ product antiporter CaiT. Proceedings of the National Academy of Sciences of USA 110:17296-17301. doi: 10.1073/pnas.1309071110.

Karmazyn M, Gan XT, Humphreys RA, Yoshida H, Kusumoto K. 1999. The myocardial Na(+)-H(+) exchange: structure, regulation, and its role in heart disease. Circulation Research 85:777-786. doi: 10.1161/01.RES.85.9.777.

Karplus PA, Diederichs K. 2012. Linking crystallographic model and data quality. Science 336:1030-1033. doi: 10.1126/science.1218231.

Krissinel E, Henrick K. 2004. Secondary-structure matching (SSM), a new tool for fast protein structure alignment in three dimensions. Acta Crystallographica Section D Biological Crystallography 60:2256-2268. doi: 10.1107/ S0907444904026460.

Lee C, Kang HJ, von Ballmoos C, Newstead S, Uzdavinys P, Dotson DL, Iwata S, Beckstein O, Cameron AD, Drew D. 2013. A two-domain elevator mechanism for sodium/proton antiport. Nature 501:573-577. doi: $10.1038 /$ nature12484.

Liu Q, Zhang Z, Hendrickson WA. 2011. Multi-crystal anomalous diffraction for low-resolution macromolecular phasing. Acta Crystallographica Section D Biological Crystallography 67:45-59. doi: 10.1107/S0907444910046573.

McCoy AJ. 2007. Solving structures of protein complexes by molecular replacement with Phaser. Acta Crystallographica Section D Biological Crystallography 63:32-41. doi: 10.1107/S0907444906045975.

McTernan PM, Chandrayan SK, Wu CH, Vaccaro BJ, Lancaster WA, Yang Q, Fu D, Hura GL, Tainer JA, Adams MW. 2014. Intact functional Fourteen-subunit Respiratory membrane-bound [NiFe]-Hydrogenase Complex of the hyperthermophilic archaeon pyrococcus furiosus. The Journal of Biological Chemistry 289:19364-19372. doi: 10.1074/jbc.M114.567255.

Meier T, Krah A, Bond PJ, Pogoryelov D, Diederichs K, Faraldo-Gomez JD. 2009. Complete ion-coordination structure in the rotor ring of Na+-dependent F-ATP synthases. Journal of Molecular Biology 391:498-507. doi: 10.1016/j.jmb.2009.05.082.

Pannu NS, Waterreus WJ, Skubak P, Sikharulidze I, Abrahams JP, de Graaff RA. 2011. Recent advances in the CRANK software suite for experimental phasing. Acta Crystallographica Section D Biological Crystallography 67:331-337. doi: 10.1107/S0907444910052224.

Paulino C, Kühlbrandt W. 2014. pH- and sodium-induced changes in a sodium/proton antiporter. eLife 3:e01412. doi: 10.7554/eLife.01412.

Penmatsa A, Wang KH, Gouaux E. 2013. X-ray structure of dopamine transporter elucidates antidepressant mechanism. Nature 503:85-90. doi: 10.1038/nature12533.

Roux B, Berneche S, Egwolf B, Lev B, Noskov SY, Rowley CN, Yu H. 2011. Ion selectivity in channels and transporters. The Journal of General Physiology 137:415-426. doi: 10.1085/jgp.201010577.

Schulz S, Iglesias-Cans M, Krah A, Yildiz O, Leone V, Matthies D, Cook GM, Faraldo-Gomez JD, Meier T. 2013. A new type of na(+)-driven ATP synthase membrane rotor with a two-carboxylate ion-coupling motif. PLOS Biology 11: e1001596. doi: 10.1371/journal.pbio.1001596.

Schushan M, Rimon A, Haliloglu T, Forrest LR, Padan E, Ben-Tal N. 2012. A model-structure of a periplasm-facing state of the NhaA antiporter suggests the molecular underpinnings of $\mathrm{pH}$-induced conformational changes. The Journal of Biological Chemistry 287:18249-18261. doi: 10.1074/jbc.M111.336446.

Shannon RD. 1976. Revised effective ionic-radii and systematic studies of interatomic distances in halides and chalcogenides. Acta Crystallographica Section A 32:751-767. doi: 10.1107/S0567739476001551.

Sheldrick GM. 2010. Experimental phasing with SHELXC/D/E: combining chain tracing with density modification. Acta Crystallographica Section D Biological Crystallography 66:479-485.

Shen A, Lupardus PJ, Morell M, Ponder EL, Sadaghiani AM, Garcia KC, Bogyo M. 2009. Simplified, enhanced protein purification using an inducible, autoprocessing enzyme tag. PLOS ONE 4:e8119.

Studier FW. 2005. Protein production by auto-induction in high density shaking cultures. Protein Expression and Purification 41:207-234. doi: 10.1016/j.pep.2005.01.016.

Tao Z, Gameiro A, Grewer C. 2008. Thallium ions can replace both sodium and potassium ions in the glutamate transporter excitatory amino acid carrier 1. Biochemistry 47:12923-12930. doi: 10.1021/bi8017174.

Villeret V, Huang S, Fromm HJ, Lipscomb WN. 1995. Crystallographic evidence for the action of potassium, thallium, and lithium ions on fructose-1,6-bisphosphatase.Proceedings of the National Academy of Sciences of USA 92:8916-8920. doi: 10.1073/pnas.92.19.8916.

Vinothkumar KR, Smits SH, Kühlbrandt W. 2005. pH-induced structural change in a sodium/proton antiporter from Methanococcus jannaschii. The EMBO Journal 24:2720-2729. doi: 10.1038/sj.emboj.7600727.

Williams KA. 2000. Three-dimensional structure of the ion-coupled transport protein NhaA. Nature 403:112-115. doi: $10.1038 / 47534$.

Williams KA, Geldmacher-Kaufer U, Padan E, Schuldiner S, Kühlbrandt W. 1999. Projection structure of NhaA, a secondary transporter from Escherichia coli, at 4.0 A resolution. The EMBO Journal 18:3558-3563. doi: 10.1093/emboj/18.13.3558.

Yamashita A, Singh SK, Kawate T, Jin Y, Gouaux E. 2005. Crystal structure of a bacterial homologue of $\mathrm{Na}+$ / $\mathrm{Cl}$-dependent neurotransmitter transporters. Nature 437:215-223. doi: 10.1038/nature03978.

Zhang KY, Cowtan K, Main P. 1997. Combining constraints for electron-density modification. Methods Enzymol 277:53-64. 